$$
D \circ E / P C / 9=295-T 3
$$

\title{
PYRITE SURFACE CHARACTERIZATION AND \\ CONTROL FOR ADVANCED FINE COAL \\ DESULFURIZATION TECHNOLOGIES
}

$\mathrm{DOE} / \mathrm{PC} / 90295--\mathrm{T} 3$

DE9 2005140

DOE Grant No: DE-FG22-90PC90295

First Annual Report

(Sept. 1, 1990--Aug. 30, 1991)

by

Xiang-Huai Wang (Principal Investigator)

J. W. Leonard, B.K. Parekh (Co-PIs).

Chengliang Jiang and A.M. Raichur (Graduate Students)

Department of Mining Engineering and

Center for Applied Energy Research,

University of Kentucky,

\section{DISCLAIMER}

This report was prepared as an account of work sponsored by an agency of the United States Government. Neither the United State: Government nor any agency thereof, nor any of their bility for the accuracy, warranty, express or implied, or assumes any legal liability or responsiprocess disclosed, or represents that or usefulness of any information. apparatus, product, or ence herein to any specific commer its use would not infringe privately owned rights. Refermanufacturer, or otherwise does mendation, or favoring by hes not necessarily constitute or imply its endorsement, recomand opinions of authors expressed States Government or any agency thereof. The views United Siates Government or any agency thereof. necessarily state or reflect those of the

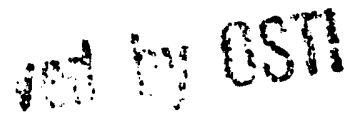

IEC 301991 


\section{TABLE OF CONTENTS}

Summary

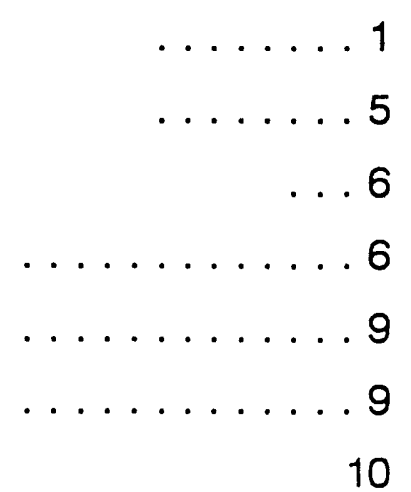

Introduction

Progress and Accomplishments

II. Results and Discussion

A. Surface Hydrophobicity Characterization by Contact Angle Titration . . 12

B. Surface Wettability Characterization by Film Flotation Tests

C. Characterization of Pyrite Surface Energetics

D. Characterization of Pyrite Surface Electrical Properties 16

E. Open-Circuit Potential Measurements 16

F. Electrochemistry and Oxidation of Pyrite Surfaces

(I). In Acidic to Neutral Solutions

(II). In Alkaline Solutions

References 


\section{SUMMARY}

This annual report summarizes the studies made during the first project year period, i.e., from September 1, 1950 to August 31, 1991, for the project entitled "Pyrite surface characterization and control for advanced fine coal desulfurization technologies", DE-FG22-90PC90295.

The objective of this project is to conduct extensive studies on the surface reactivity of pyrite by using electrochemical, surface analysis, potentiometric and calorimetric titration, and surface hydrophobicity characterization techniques and to correlate the alteration of the coal-pyrite surface with the efficiency of pyrite rejection in coal flotation. The products as well as their structure, the mechanisms and the kinetics of the oxidation of coal-pyrite surfaces and their interaction with various chemical reagents will be systematically studied and compared with that of mineral-pyrite and synthetic pyrite to determine the correlation between the surface reactivity of pyrite and the bulk chemical properties of pyrite and impurities. The surface chemical studies and the studies of floatability of coal-pyrite and the effect of various parameters such as grinding media and environment, aging under different atmospheres, etc. on thereof, are directed at identifying the causes and possible solutions of the pyrite rejection problems in coal cleaning.

Sample acquisition and preparation, i.e., Task I of the project, were accomplished during the first five months. Five high quality coal pyrite samples were collected from the following coal seams: Illinois No.6, Kentucky No.9, Pittsburgh No.8, Upper Freeport and Sichuan, China, respectively. High purity mineral pyrite samples were also acquired. Synthetic single pyrite crystals of $5 \mathrm{~mm}$ in size and microcrystalline pyrite particles of average particle size $6 \mu \mathrm{m}$ were successfully obtained. The purity of the synthetic pyrite samples is above $99.9 \%$.

The surface hydrophobicity of coal-pyrites and ore-pyrites has been characierized 
by film flotation tests and contact angle measurements. The film flotation results indicate that pyrite samples from different sources have quite similar surface hydrophobicity which is close to that of the coal (Upper Freeport) when prepared by dry grinding. The average critical surface tension of wetting ( $\gamma$ ) determined by film flotation tests is 35 to 45 dyne/cm. Surface cleaning by ultrasonication and washing with EDTA leads to lower critical surface tension of wetting $\left(\gamma_{c}\right)$, indicating that the hydrophilic surface layers are selectively removed. Wet grinding affects adversely the surface hydrophobicity of the pyrites.

Contact angles of coal-pyrite and ore-pyrite have been measured under different environment. When contact angle was measured under air and nitrogen, both the contact angle and the water droplet decrease with increasing the contact time. The rate of decrease depends on the source of the sample, solution phi and the atmosphere. The contact angle of water droplet under $n$-alkanes is quite stable. The contact angle of both coal-pyrite and ore-pyrite varies with solution $\mathrm{pH}$ and shows a maximum around PZC. Freshly ground coal-pyrite surfaces, when reacting with oxygen-sturated solutions, become more hydrophobic; while after reacting with $\mathrm{CO}_{2}$-saturated solutions, the contact angle descreases slightly. In all cases, freshly polished coal-pyrite and ore-pyrite surfaces exhibit a contact angle of 40-60 degrees, indicating that freshly polished pyrite surfaces are inherently hydrophobic.

The surface energetics of coal-pyrites and ore-pyrites has been investigated by a new method developed recently by the PI of this project. The dispersion component of surface free energy of ore- and coal-pyrites was found to be essentially the same, about $50-55 \mathrm{erg} / \mathrm{cm}^{2}$. However, the acid-base interaction energy between the pyrite surface and water at $\mathrm{pH}=7.2$ depends on the individual sample. The acid-base interaction energy of the surface with water for the ore-pyrite (SPPY) is about $80 \mathrm{erg} / \mathrm{cm}^{2}$, while that of the coal-pyrite (ICPY) is about $50 \mathrm{erg} / \mathrm{cm}^{2}$. This indicates that the coal-pyrite surface is more hydrophobic than the ore-pyrite.

Zeta-potential measurements show that the coal-pyrite samples have an IEP at pH 
4-6 which is close to that of coals. The ore-pyrite and synthetic microcrystalline exhibit IEPs at around $\mathrm{pH}=7$. There is, in general, a good relationship between the zeta-potential and the contact angle variation with $\mathrm{pH}$. At $\mathrm{pH}=\mathrm{IEP}$, maximum contact angle is observed.

The oxidation and reduction behavior of coal-pyrites, ore-pyrites and synthetic pyrite single crystals have been studied using electrochemical methods, including cyclic voltammetry, rotating-disc electrode technique, open-circuit potential measurements and steady-polarization measurements. It was found that an oxidation layer is rapidly formed on the pyrite surfaces when the electrodes are wet polished under air. Two groups of the electrodes studied can be distinguished from the electrochemical reactivity. The Pittsburgh No.8 and Kentucky No.9 coal-pyrites belong to one group, while the rest belong to the group. For each group, the electrochemical reactivity is quite similar. No well-defined oxidation or reduction peaks have been observed for the Kentucky No.9 and Pittsburgh No.8 coal-pyrite electrodes in all the solutions studied.

The electrochemical behavior of the other group of electrodes can be summarized as follows. In highly acidic solutions ( $\mathrm{pH}=0.5--3$ ), the anodic (oxidation) process has a Tafel slope of about $100 \mathrm{mV}$. The Tafel slope is independent of rotation, sweep rate, the presence of $\mathrm{Fe}^{3+}$, and most importantly, the source of pyrite samples. The Tafel slope becomes about $120 \mathrm{mV}$ in neutral solutions. In the $\mathrm{pH}$ range $0-8.5$, a sharp reduction peak is observed at a potential of about $400 \mathrm{mV}$ vs SCE on the negative-going sweep when the preceding positive-going sweep potential is over $600 \mathrm{mV}$ vs SCE. This reduction peak is characterized by the following features:

(1) the peak potential is nearly independent of the potential limit of the preceding positive-going sweep;

(2) the peak current increases with increasing potential limit;

(3) the Tafel slope is about $90 \mathrm{mV}$;

(4) the peak current increases with increasing the positive potential limit;

(5) the reaction is rotation-dependent, the peak disappears when the electrode is rotated;

(6) the peak potential and peak current are independent of the solution $\mathrm{pH}$; 
(7) the peak current increases with increasing the ferric ion concentration in solution and becomes a plateau at higher ferric ion concentrations.

This reaction has been identified as the reduction of ferric ions to ferrous irons.

In highly alkaline solutions $(\mathrm{pH}=10-12)$, a rotation-dependent oxidation peak is observed at a potential of about $300 \mathrm{mV}$ vs SCE. This oxidation peak is characterized by the following features:

(1) the peak potential is nearly independent of the solution $\mathrm{pH}$ in the $\mathrm{pH}$ range of $10-12$.

(2) the peak current increases with increasing solution $\mathrm{pH}$.

(3) the peak becomes a plateau when the electrode is rotated, and the limiting current is a linear function of the square root of rotation speed;

(4) The Tafel slope of the process is about $120 \mathrm{mV}$.

The reaction is identified as the adsorption and discharge of hydroxide ions on the pyrite surfaces. This process controls the initial oxidation process of the pyrite surface. 


\section{INTRODUCTION}

In many U.S. coal deposits, pyritic sulfur is predominant and its removal from the coal could meet acid rain control legislation standards. The first requirement for the removal of intimately locked fine pyritic sulfur from coals is to grind the coal to an ultrafine size to liberate pyrite particles. Such ultrafine pyrite particles cannot be separated from coal by conventional physical washing methods. Therefore, advanced coal cleaning technologies need to be developed. Froth flotation, agglomeration and flocculation have shown the potential for removing pyritic sulfur from coal. These techniques are based on differences in the surface properties, particularly the hydrophobicity, of coal and coalpyrite. However, rejection of pyrite from coal by these surface-based techniques has been a very elusive problem. It has been observed that the rejection of pyrite varies greatly from one coal seam to another or even from the day to day operation within the same coal seam. The causes of such problems are complex and have not been well characterized. In addition to the superficial chemical alteration of pyrite, such as surface oxidation and adsorption of various chemicals on pyrite surfaces, bulk chemical composition variation may also greatly change surface properties and reactivity of pyrite. Stoichiometrically, pyrite has the chemical composition of iron disulfide, $\mathrm{FeS}_{2}$. However, natural iron disulfides show a composition deviation from $\mathrm{FeS}_{2}$, with the ratio of $\mathrm{S} / \mathrm{Fe}$ varying from 1.9 to 2.1 . They may also contain a great amount of impurities as crystalline inclusions. This is particularly true for coal pyrites which usually contain carbon and organic materials. Natural iron disulfides occur in two crystalline modifications: pyrite and marcasite. Pyrite has a cubic structure, while marcasite has an orthorhomic structure. Their chemical reactivitY, particularly to oxygen, is considerably different. Furthermore, the geological conditions for the formation of pyrite from different sources, especially in coal, are different. Finally, pyrite may exist in p-type or n-type semiconducting form. The aim of this project is to conduct comparative studies on the surface properties of coalpyrite from different coal deposits, mineral pyrite and synthetic pure pyrite. Such systematic studies will elucidate the correlation of pyrite surface properties/reactivity with bulk chemical composition, structure, impurities and superficial alteration. In this project, 
these bulk chemical parameters will be characterized in detail and their contribution to the surface properties of pyrite will be systematically studied.

\section{DESCRIPTION OF EXPERIMENTAL APPROACHES}

In order to characterize the surface properties and reactivity of pyrite from different sources and to clarify whether there is a defined relationship between the bulk physical and chemical properties and the surface reactivity and properties, multiple research techniques/methods are required. In the present research, the following techniques have been used.

\section{A. Electrochemical Techniques}

Electrochemical techniques have been widely used to study the nature, mechanisms and kinetics of redox reactions at sulfide surfaces. The following electrochemical techniques were employed during the first year of the project.

\section{Mixed-Potential Measurements.}

For any electrochemical systems, there exist a potential at which the anodic oxidation and cathodic reduction reactions occurs at the same rate, so that the partial currents for the anodic and cathodic processes are equal and the net overall current is zero. This potential is called mixed-potential, or open-circuit potential. In the flotation electrochemistry, it is also called "rest-potential". The mixed-potential measurement can be useful in studying the surface reactions of sulfide minerals. For example, by comparing the mixed-potential with the thermodynamic potential of different reactions, it is possible to conjecture what kind of reactions occurring at the electrode/solution interface. Furthermore, by measuring the mixed-potential of an electrode as a function of time, slow transformation of the surface as well as surface product films can be detected.

\section{Potentiodynamic Sweep (PDS)}

In the PDS the electrode potential is changed slowly and the current is measured 
as a function of potential. The change rate of potential must be sufficiently slow so that the reaction could occur under steady-state or equilibrium conditions. Hence, the technique is also called steady-state polarization. In most cases, a rotating electrode is used to have a controlled mass transport. If the electrode reaction is activation-controlled, then the plot of $\log$ (current) against potential will give a straight line. This is the so-called Tafel plot. From the Tafel slope and its dependence on the chemical parameters like pH and ion concentrations, it is possible to derive much information about the reaction mechanisms and kinetics. Since the technique simulates the equilibrium conditions, it is very usefu! for studying reactions occurring under conditions like weathering, leaching etc..

\section{Cyclic Voltammetry}

In the CV technique, the electrode potential is changed constantly by a specified rate and the current is measured as a function of potential. Since the sweep rate can be very high, the $\mathrm{CV}$ technique differs from the PDS technique in that the steady-state or equilibrium conditions are not necessarily met. The hydrodynamics can also be controlled by rotating the electrode. Nonequilibrium electrochemical processes, like adsorption, and the reversibility of the reactions can all be identified.

\section{Experimental Set-UP:}

A standard three-electrode system is used. A pyrite electrode is the working electrode. The counter electrode is a platinum electrode. The potentials were measured against a saturated calomel electrode (SCE) which potential is related to the standard hydrogen scale by the following relationship:

$$
E_{S C E} \equiv E_{h}-245(m V)
$$

The electrochemical system used in the present study consists of a EG\&G Princeton Applied Research (PAR) Model 273 potentiostat/galvanostat, a Salatron Model $1255 \mathrm{HF}$ frequency response analyzer (FRA) and a PAR model 660 rotating-disc electrode apparatus. The system, including data acquisition, is operated by a 386 IBM computer. 
All other measurements were performed with a user-modified Headstart Creative Software.

Pyrite Electrodes: The respective pyrite samples were cut to a cubic shape and attached to brass rods using conducting carbon glue. The electrodes were molded in epoxy resin and one face was initially ground using SiC polishing papers 400 and 600 grit to expose to the electrolyte. Before each measurement, the electrode was polished using $0.05 \mu \mathrm{m}$ Alumina in air with distilled, deionized and deoxygenated (DDD) water and rinsed with DDD water. The measured geometric surface areas were used for calculating the current density.

Rotating-Disc Electrode (RDE): The rotating-disc electrode (RDE) technique enable one to study the effect of rotating the electrode on the reaction processes occurring at the electrode surface, and thereby to distinguish the solution species involved reactions from solid species reactions. The EG\&G Princeton Applied Research manufactured RDE system has several drawbacks. Therefore, the RDE has been modified. As shown in Fig.3, after modification, only the lower portion of the shaft rotates, while the upper part remains stationary. This enables the upper portion to keep tight contact with the cell lip. The cell will thus be sealed from the ambient, which prevent any oxygen/air entrance into the electrochemical cell. The atmosphere in the cell can be well controlled.

Interchangeable Thin-section Rotating-Disc Electrode (TSRDE): In order to conduct XPS, AES and SEM studies of the chemical nature and structure of the products formed on the pyrite electrode surface during electrochemical experiments, a special electrode, called as interchangeable thin-section rotating-disc electrode (TSRDE) has been constructed. This permits the quick withdraw of the thin-section of pyrite from the electrochemical cell and the transfer of the thin section to the high vacuum sample chamber of the XPS or AES for surface chemical analysis. Plotting the peak intensities of a element (e.g., iron) vs time yields the reaction kinetics and thickness of products. Though such measurements are still not real-time, they can be considered parallel to the electrochemical measurements. 


\section{B. Contact Angle Measurements}

The hydrophobicity characterization of pyrite surfaces have been conducted by measuring the contact angles with a Ramer-Hart contact angle goniometer. An environmental chamber for the contact angle goniometer has been set up. Using this chamber, the atmosphere and humidity for the contact angle measurement using the sessile drop method can be controlled. Contact angle measurements can be carried out in nitrogen, oxygen, carbon dioxide or the atmosphere simply by connecting the environmental chamber to the gas plugs. The relative humidity is controlled by passing the gas through a bottle which is filled with distiled water.

\section{Film Flotation/Micro Flotation}

The surface hydrophobicity of solid powders has been studied using film flotation tests. This technique was developed by Fuerstenau and co-workers [1987] and Diao [1990] for the surface characterization of coal powders. Their studies showed that it is a good technique for characterizing the surface hydrophobicity of fine particles. In the film flotation tests, aquatic methanol solutions (i.e., mixtures of water with methanal at different vclume ratio) possessing a wide range of surface tensions (from 20 to $72 \mathrm{dyne} / \mathrm{cm}$ ) are used. 100 milligrams of particles of size $100 \times 150$ mesh are carefully (in single layer of particles) spread over the surface of aquatic methanal solution. Depending on the surface hydrophobicity of the particles, portions of the particles will stay at the surface (hydrophobic), while others are immersed in the solution (hydrophilic). The floated particles are then collected by vacuum sucking through a small glass tube, dried and weighed. The percentage of the floated can be calculated and is plotted against the surface tension of the sclution.

\section{Zeta-Potential Measurements}

The surface electrical properties of pyrite particles has been studied by zetapotential measurements using a Zee-100 Zeta-Meter. The measurements were conducted 
in $0.01 \mathrm{M} \mathrm{NaClO}_{4}$ or $0.01 \mathrm{M} \mathrm{NaNO}_{3}$ solutions. The average particle size used for the zetapotential measurements was about $6 \mu \mathrm{m}$. The suspension of pyrite particles ( 5 grams in $100 \mathrm{ml}$ solution) was first conditioned (under nitrogen) at the specified $\mathrm{pH}$ for 10 minutes. Then the suspension was allowed to settle for two minutes. A portion of the top suspension was taken for the zeta-potential measurements.

\section{PROGRESS AND ACCOMPLISHMENTS}

\section{Acquisition and Preparation of Samples}

Several iron sulfide samples were acquired from the Wards Natural Science Establishment Inc., including cubic single pyrite crystals (from Spain), poritohedral pyrite crystals (from Peru and Arizona), marcasite crystals (from Indiana), and pyrrhotite crystals (from Mexico). These samples are relatively pure and no further cleaning is needed. Five coal pyrite samples were collected from the following coal mines: Illinois No.6, Kentucky No.9, Pittsburgh No.8, Upper Freeport and Shichuan, China, respectively. The illinois \#6 coal pyrite samples, obtained from the Wards National Science Established Inc., New York and known as "lily pyrite pad", are large thin lumps. The samples show good crystallinity and are considered as high quality and purity. All the other coal-pyrite samples are massive lumps and contain coal particles. The purification of samples was performed as follows. Samples were first manually crushed and the coal particles were removed by hand. Good quality coal pyrite particles were selected for making electrode and pallets for electrochemical and contact angle studies. Part of the samples was then crushed and ground to -100 mesh and cleaned by electrostatic separation method to remove coal particles. The cleaning procedures were repeated for a number of time. The final sample contains about $88 \%$ pyrite (for Kentucky \#9 coal pyrite sample). The prepared samples was stored in a nitrogen atmosphere in a desiccator under nitrogen at $-20^{\circ} \mathrm{C}$.

Pure synthetic pyrite crystals produced by non-wet chemical methods were also 
obtained. The synthetic pyrite crystals were about $5 \mathrm{~mm}$ in size. The chemical composition of the pyrite is $\mathrm{FeS}_{1.93}$, i.e., sulfur-deficient. The purity of the sample is over $99.95 \%$. A number of wet chemical methods of preparation and purification of pyrite have been tested and the studies are still in progress. These tests demonstrate that the synthesis of pyrite crystals by wet chemical methods is difficult. Experimental conditions are extremely critical. At room temperature, mixing ferric perchlorate and sodium disulfide in a brownish precipitate. Acidifying and aging the precipitate for two days produced micro particles which appear to be close to pyrite. However, these particles remain in the micron size and show nu growth even upon prolonged reaction. Average particle size of th syrithesized particles is $6 \mu \mathrm{m}$. The chemical composition analysis of the prepared sample indicates that this sample is iron-rich.

Table 1 shows the source, crystal form and major chemical compositions of the pyrite samples used in the project. Based on the similarity of the electrochemical behavior of the electrodes, they can be seperated into two classes: class A and B. PAPY and KYPY belong to class $B$, while the rest all belong to class $A$.

Table 1 Pyrite electrodes used in the electrochemical studies

$\begin{array}{llcr}\text { Abbreviation } & \text { Source } & \text { Semiconducting Properties } & \text { Class } \\ \text { PAPY } & \text { Coal-pyrite from Pittsburgh No.8 Coal } & \text { n-type } & \text { B } \\ \text { KYPY } & \text { Coal-Pyrite from Kentucky No. 9 Coal } & \text { n-type } & \text { B } \\ \text { UFPY } & \text { coal-pyrite from Upper Freeport coal mine } & \text { n-type } & \text { B } \\ \text { SPPY } & \text { Ore Pyrite from Span } & \text { p-type } & \text { A } \\ \text { PUPY } & \text { Ore-Pyrite from Peru } & \text { p-type } & \text { A } \\ \text { SWPY } & \text { Ore-Pyrite from Boliden, Sweden } & \text { p-type } & \text { A } \\ \text { CNPY } & \text { Coal Pyrite from Sichuan Coal Seam, China } \quad \text { p-type } & \text { A } \\ \text { ICPY } & \text { Coal-pyrite from Illinois No.6 coal (Lilly) } & \text { n-type } & \text { A } \\ \text { MarC } & \text { Marcasite from Indiana } & \text { p-type } & \text { A } \\ \text { SYNPY } & \text { Synthesized by vapor transportation } & \text { p-type } & \text { A }\end{array}$




\section{Results and Discussion}

\section{A. Surface Hydrophobicity Characterization by Contact Angle Titration.}

Early studies showed that when the contact angle measurements were made under air or under nitrogen, the contact angle of water droplet on the pyrite surfaces decreases and the water droplet shrinks as the sontact time increases (cf., 1st and 2nd quarterly reports). The water droplet disappears if prolonged contact time is allowed. The decreasing rate of the contact angle and water droplet size depend on the solution $\mathrm{pH}$ and the atmosphere. In general, the rate of decrease is higher under air than under nitrogen, though the humidity is the same. In the $\mathrm{pH}$ range where maximum contact angles are displayed, the rate of decrease is minimum. The results were reported in our first and second quarterly reports [Wang, Leonard and Parekh, Dec. 1990 and March 1991]. In order to understand the phenomena, comparative studies were conducted of contact angle of water droplet on pyrite surfaces under $n$-alkanes. Figure 1 compares the results measured under different environment. It can be seen that the contact angle of water droplet under hexane is stable and remains almost constant for the time length studied (60 minutes). The results indicate that the decrease of contact angle and the shrinkage of water droplet are probably due to the evaporation of water. However, the much greater decrease rate of contact angle and water droplet size under air than under nitrogen suggests that oxidation is also an important factor. Probably, oxidation is still significant under nitrogen, as it is known that removal of trace oxygen is extremely difficult.

Figure 2 shows the contact angles (measured under air) as a function of solution $\mathrm{pH}$ for ICPY (Illinois No.6 coal pyrite). The contact angle values of "fresh" surfaces were obtained by extrapolation to zero coriact time. They may be close to the true contact angle and represent the hydrophobicity of the freshly polished pyrite surfaces. It can be seen that the contact angle is essentially a constant. As has described above, the contact angle decreases as the contact time increases. After five minutes, the contact angle varies 
with the solution $\mathrm{pH}$ and exhibits two maxima at $\mathrm{pH}$ around 5 and 7.5 , respectively.

Similar results are obtained for other pyrite samples studied. Figure 3 shows the results for the ore-pyrite sample SPPY (contact angle measured under nitrogen ). It is interesting to point out that the maximum contact angles coincide well with the isoelectrical point (IEP), as shown in the diagrams. We will discuss these findings in more detail later.

A series of experiments were conducted to examine the effect of different gases on the surface hydrophobicity of pyrite. Figure 4 shows the contact angle variation with time for an Illinois No.6 coal-pyrite. In this study, the sample was first polished then put in different solutions which was saturated with one of the gases (nitrogen, oxygen or carbun dioxide). Note that in case of carbon dioxide, it was found that the $\mathrm{pH}$ of the solution dropped to about 4 after bubbling $\mathrm{CO}_{2}$ gas for ten minutes. $\mathrm{NaOH}$ solution was added to the solution to keep the solution $\mathrm{pH}$ at the neutral range (6.5-7.5). At a specified time, the pallet was taken out from the solution, rinsed with distilled water and put in the measuring chamber. After about one minute (to let the surface dry), three water droplets were put on the different surface sites and the contact angle of each water droplet the surface was measured. The values in Fig. 4 were generally the average values of 3 separate tests (i.e., 9 readings). It is interesting to see that the contact angle of the pyrite sample changes with the time that it has been immersed in the solution. Under oxygen saturated solutions, the contact angle first increases, reaches a maximum value of close to 80 degree, and then decreases upon prolonged reaction. Under nitrogen, the contact angle also increases with time but much more slowly than under oxygen. These studies indicates that slightly to moderately pyrite surfaces are more hydrophobic than the freshly cleaned surface. Interestingly, under carbon dioxide, the contact angle decreases with time that the surface exposed. However, it should be noted that initial contact angle of the pyrite surface corresponding to "clean" surfaces is about 25 degrees lower than the values obtained by extrapolation (as shown in Fig.2). The exact reason is not known, but may be due to the difference in the solutions used in the contact measurements. In the contact angle titration studies, the water 'solutions used for contact 
angle measurement were buffered solutions containing $0.01 \mathrm{M} \mathrm{NaNO}_{3}$ In other cases, deionized water was used. So there is a possibility that the $\mathrm{pH}$ of the droplet might have changed after contacting the surface.

\section{B. Surface Wettability Characterization by Film Flotation.}

The results of film flotation tests are presented in Fig. 5 for the four pyrite samples (KYPY, PAPY, ICPY and PUPY) prepared by dry grinding using a mortar and pestle. The results show that the surface hydrophobicity of the three coal-pyrites are quite similar and have an average $\gamma_{c}$ (i.e., at $50 \%$ floated) $40-48$ dyne $/ \mathrm{cm}$. The ore-pyrite from Peru (PUPY) is slightly more hydrophobic than the coal-pyrite samples and exhibits a $\gamma_{c}$ of about 34 dyne $/ \mathrm{cm}$. However, when the samples were prepared by wet grinding and then dried, then the ore-pyrite (PUPY) is more hydrophilic than all the coal-pyrite samples.

Figure 6 compares the film flotation results of the coal, coal-pyrite and ore-pyrite after su' 'face cleaning by ultrasonication. It can be seen that after ultrasonication, the coalpyrite samples become almost identical with a $\gamma_{\mathrm{c}}$ value of about 37 dyne/cm which is quite close to that of coal (from Upper Freeport) and the ore-pyrite (from Peru). The ultrasonication has only slight effect on the $\gamma_{c}$ of the coal and the ore-pyrite. The effects of surface "cleaning" by washing with EDTA-a strong iron-complexing agents has similar effect to the ultrasonication treatment, as shown in Fig.7. The results are in good agreement with that of Wang and Forssberg [1990] and Chander et al [1991]. Wet grinding of the prepared samples renders the pyrite samples more hydrophilic, while it has little effect on the coal sample studied.

\section{Characterization of Pyrite Surface Energetics.}

Contact angle measurements under air or nitrogen as described above can provide useful information on the surface hydrophobicity but the information is limited to qualitative 
nature. Film flotation tests can yield quantitative values of the critical surface tension of wetting $(\gamma)$ of solids. $\gamma_{c}$ is a good estimate of the surface dispersion free energy. Since, the total surface free energy (i.e., total surface tension) consists of two components: the dispersion free energy and the acid-base free energy, film flotation tests can only give useful information on one component. The acid-base free energy and interaction energy cannot be characterized by the two methods described above. Fowkes [1990], Good, Van-Oss and their coworkers [1990, 1991] showed that the acid-base component is of great importance in controlling the surface behavior of solids. Several methods have been suggested in their publications. However, these methods either require highly complex and expensive instrumentation or possess insufficient accuracy.

Recently, Wang [1991a] has developed a simple and reliable method for evaluating the surface free energy components of solids. Brief description of the method was presented by Wang and Parekh [1991] and in the 3rd quarterly report. Details of the method and theory will be published elsewhere.

Figiures 8 and 9 show some typical results generated by the new method for the SPPY and ICPY, respectively. Linear regression analysis gives a slope of 14.8 and intercept of 80 for the ore-pyrite. From this, the dispersion surface free energy component is evaluated to be $52 \mathrm{erg} / \mathrm{cm}^{2}$ for the ore-pyrite (from Span). Similarity, Figure 3 gives a slope of 15.2 , thus yielding a dispersion surface free energy of $56 \mathrm{erg} / \mathrm{cm}^{2}$. These results demonstrates that the dispersion component of the surface free energy of the Illinois No.6 coal-pyrite and the ore-pyrite are essentially the same. This is in good agreement with the results obtained by the film flotation tests (reported in the third quarterly report), since it has been shown that the $\gamma_{c}$ value closely matches the $\gamma_{s}{ }^{d}$ of $a$ solid surface. However, the acid-base (or polar) interaction energy for the ICPY with water is about $52 \mathrm{erg} / \mathrm{cm}^{2}$, considerably lower than that of ore-pyrite (SPPY) which is 80 $\mathrm{erg} / \mathrm{cm}^{2}$. The results suggest that coal-pyrite ICPY is more hydrophobic than ore-pyrite SPPY.

The above studies show that this new method can give accurate quantitative 
information on the surface energetics of a solid and is very useful for studying high energy surfaces like pyrites.

\section{Characterization of Pyrite Surface Electrical Properties.}

The zeta-potential of various coal-pyrite anc ore-pyrite as a function of $\mathrm{pH}$ is shown in Fig.10. The isoelectrical point (IEP) of the pyrite samples differ from each other. The electrokinetic behavior of coal-pyrite KYPY and PAPY are quite similar to that of the coals, with IEPs being at $\mathrm{pH} 4-6$, as shown in Fig.11. The electrokinetic behavior of ore-pyrite is similar to that of synthetic pyrite microcrystalline particles and exhibits their IEPs at around $\mathrm{pH} 7$. In Figs. 2 and 3 , the zeta-potentials are compared with the contact angles as a function of solution $\mathrm{pH}$ for ICPY and SPPY. The results demonstrate that there is a close relationship between the zeta-potential and contact angle. It is interesting to note that all the pyrite samples display maximum contact angle at $\mathrm{pH}$ around the IEP. Similar results were obtained for coals. Recently, Wang [1991b] developed thermodynamic equations and found that at $\mathrm{PZC}$, a solid/solution interface has maximum interfacial tension ( $\gamma$ ) and maximum contact angle. Thus, the experimental results shown above are supported by thermodynamics.

\section{E. Open-Circuit Potential Measurements.}

Figure 12 show that open-circuit potential of the Illinois No.6 coal pyrite electrode under various chemical and hydrodynamic conditions. Each measurement corresponds to a fresh surface (polished with $0.05 \mu \mathrm{m}$ Alumina under air). In the absence of ferric ions, the electrode has an open circuit potential of 250-275 mV (vS SCE). Upon contact with the electrolyte solution, the open-circuit potential decreases slightly if the electrode is stationary, i.e., when the solution is quiescent. However, when the electrode is rotated, the open-circuit potential increases gradually. Furthermore, when the electrode is first stationary and then rotated after contact with the solution for some time, the electrode 
potential first increased sharply when the rotation is turned on and then increases slowly. The magnitude of increases depends on the rotation speed. In the presence of ferric ions, the electrode potential is much higher than that in the absence of ferric ions. A increase in the open-circuit potential indicates an increase in the oxidation degree or rate of the electrode surface. It have been found that the open-circuit potentials for the synthetic pyrite electrode and the ore pyrite electrode are almost the same.

\section{F. Electrochemistry and Surface Oxidation of Pyrite.}

Characterization of the oxidation processes and products of pyrite surface is of great importance in understanding the nature of the inherent surface hydrophobicity of pyrites. Electrochemical techniques are powerful in identifying the nature, kinetics and mechanisms of the pyrite surface oxidation. During the first year of this project, the electrochemistry and oxidation processes of pyrite surfaces have been studied by examining the following parameters:

a. the potential at which an electrode reaction commences;

b. the effect of rotating the electrode;

c. the Tafel slopes of the electrode processes;

d. the effect of sweep potential limits, sweep rate and multiple sweeps on the electrode reactions;

e. the effect of changing the chemicals in the solution, e.g., $\mathrm{pH}$, etc..

There are, of course, drawbacks with all the electrochemicai techniques. it is easy to state that some reactions has occurred at the electrode surface. However, it is often quite difficult to determine the exact nature of the reactants/products. A large number of experimental data are required to understand one electrode process. In the quarterly reports, rationalized examples were presented for highly acidic $(\mathrm{pH}=0.5-3)$, neutral, and highly alkaline $(\mathrm{pH}=10-12)$ solutions. Here, the results obtained at different $\mathrm{pH}$ solutions are compared and analyzed systematically. 
The Pourbax diagrams (i.e., Eh-pH stability diagrams) for the iron-sulfur-water system are shown in Figs. 13 and 14. Thermodynamically, the sulfur component in pyrite should be oxidized to sulfate at higher potentials, and the iron component will be in the form of ferric hydroxide, ferric ions or ferrous ions, depending on the solution $\mathrm{pH}$ and the potential. However, the kinetics strains and the very large overpotential needed for elemental sulfur oxidation into sulfate may restrict the oxidation of the sulfur component to some metastable sulfoxyl species, for example, sulfite and/or thiosulfate. This kind of diagrams can be helpful for interpretating the electrochemical results.

\section{(I) Oxidation In Acidic to Neutral pH Solutions}

Figure 15 shows the typical cyclic voltammograms of the Illinois No.6 coal pyrite electrode in highly acidic solutions $(\mathrm{pH}=0-3)$. The initial sweeps were started at the opencircuit potentials in the negative-going direction. A reduction current peak is seen on the first negative-going sweep. This is attributed to the reduction of the surface oxidation products formed on the electrode during polishing. On the second cycle of potential sweep, the reduction peak disappears. The reduction current is independent of the electrode rotation. Similarly results were obtained for the ore and synthetic pyrite electrodes. These results indicate that the freshly wet polished surfaces of pyrite are covered by a layer of oxidation products. The chemical composition of the oxidation products cannot be identified from the results presented here. So the exact nature of the reduction reaction corresponding to the peak can not be determined at present. Previous studies have suggested two possible reaction schemes responsible for the oxidation of the pyrite surface during grinding:

Both reactions are likely reversible. Thus, a new pyrite surface can be regenerated when 
the electrode is subjected to a reduction potential.

When the first potential sweep is in the positive-going direction, a large oxidation current (peak I) is observed above $500 \mathrm{mV}$ vs SCE, Fig.16. The current increases with increasing the potential. When the electrode is stationary, a sharp reduction peak (peak II) is observed at about $450 \mathrm{mV}$ vs SCE on the reversing sweep. This peak is not observed on the rotating electrode. When the potential is further lowered, a large reduction peak (peak III) commences at $-200 \mathrm{mV}$ vs SCE and has a peak potential of 400 $\mathrm{mV}$, almost independent of electrode rotation. On the second positive-going sweep, a very broad peak (peak $\mathrm{V}$ ) is seen at about $-100 \mathrm{mV}$ vs SCE. The peak disappears on a rotating electrode.

Similar results were obtained for other pyrite electrodes of the group $\mathrm{A}$, indicating that the electrochemical behavior is nearly independent of the sources. The results are contrary to several previously reported studies (e.g., Chander and Aplan, 1990) in which the oxidation behavior of coal pyrites were found to be drastically different from that of ore pyrite. It has been found that peak II and the rotation dependence phenomenon exist in solutions upto $\mathrm{pH}=8.5$, as shown in Figs. 17 and 18. However, the reduction peak (II) appears only when the positive-going sweep potential limit is above $600 \mathrm{mV}$ vs SCE. The peak current increases with increasing the potential limit (Fig.19). The reduction peak was early suspected to be the reduction of some thiosulfoxy species formed during the preceding oxidation. However, it was found later that the peak current increases with increasing the concentration of ferric ions in the solution. Furthermore, in the presence of high concentration $\left(>1 \times 10^{-4} \mathrm{M}\right.$ ) of ferric ions, the reduction peak becomes a plateau on the rotating electrode, and the limiting current increases with increasing the ferric ion concentration, as shown in Fig.20. These results demonstrate that peak II is due to the reduction of ferric ions into ferrous ions, not thiosulfoxyl species.

The Tafel plot for peak II is shown in Fig.21. Depending on the chemical and hydrodynamic conditions in the solution, the Tafel slope (i.e., $\mathrm{dE} / \mathrm{dlog}(\mathrm{l})$ ) is $70-90 \mathrm{mV}$. This suggests that the reaction takes place according to the following processes: 
Theoretically, if reaction (A) is the rate-determining step, the Tafel slope will be $120 \mathrm{mV}$, while if reaction is the rate-determining step, then the Tafel slope is $60 \mathrm{mV}$. Thus, the reduction is probably controlled by the second step.

Figure 22 shows the Tafel plots for the oxidation of Illinois No.6 coal pyrite (ICPY) in the absence and presence of different concentratior.s of ferric ions. In the absence of ferric ions, there is a great hysteresis. The hysteresis is considerably reduced by addition of ferric ions into the solution (at low ferric concentration) and finally disappears at high ferric concentration. Similar results were obtained for the other ore-pyrite, coal-pyrite and synthetic pyrite. The Tafel slope is about $100 \mathrm{mV} / \log \{1\}$, where $\mathrm{l}$ is the current density. The Tafel plot shows no dependence on rotation, sweep rate, the presence of ferric ions and solution $\mathrm{pH}$. To understand these phenomena, various possible rout., ies have been considered and analyzed. The most possible reaction mechnaisms are one of the following two:

Mechanism I:

Mechanism II:

Tile Tafel slopes will be $120 \mathrm{mV} / \log \{\mathrm{l}\}$ for both mechanisms I and II if the first electron transfer steps, i.e, step (la) and (Ila) are the rate-determining (RD) step. If mechnanism $\mathrm{I}$ is responsible and step (Ib) is the RD ste $\mathrm{H}_{\mathrm{N}}$, then the Tafel slope is $60 \mathrm{mV} / \log \{\mathrm{l}\}$. However, if mechanism II is responsible, and step (IIb) is the RD step, then depending 
on the bulk concentration of $\mathrm{Fe}^{2+}$, the Tafel slope may be $40 \mathrm{mV} / \log \{\mathrm{l}\}$ (at high bulk $\left[\mathrm{Fe}^{2+}\right]$ or $80 \mathrm{mV} / \log \{1\}$ when bulk $\left[\mathrm{Fe}^{2+}\right]=0$. It is still not possible to identify the exact mechanisms based on our present available data. However, considering the surface hydrophobicity character seems to suggest that mechanism II maybe better fit the experimental results.

\section{(II) In Alkaline Solution}

Typical cyclic voltammograms for the class A electrode in highly alkaline solutions are shown in Fig.23. At a stationary electrode, when tho potential sweep is initiated in the positive-going direction from the mixed-potential (ca., -100 to $-150 \mathrm{mV}$, at $\mathrm{pH}=10$ ), an significant oxidation peak (peak $\mathrm{I}$ ) is observed at potential around $300 \mathrm{mV}$ vs SCE. Another prominent oxidation peak (II) appears when the potential is above 500 $\mathrm{mV}$ vs SCE. Interestingly, when the electrode is rotated, peak I becomes a plateau, while peak II shows no signiiicant change. At lower potentials, good-shaped reduction peak, III, is observed at potentials of $-800 \mathrm{mV}$ (peak III) on the negative-going sweep and oxidation peak, IV, at $-300 \mathrm{mV}$ on the second positive going direct. The currents of two peaks are not significant on the stationary electrode. In general, the results are in good agreement with published studies (Ahlberg, Forssberg and Wang, 1990].

The rotation dependence of peak $I$ is of great interest and has thus been extensively studied. Figure 24 shows the variation of the limiting current of I with rotation speed. It can be seen that the limiting current of I increases with increasing rotation speed. Furthermore, by plotting the limiting current against the square root of rotation speed, two perfectly parallel straight lines are obtair.ed, as shown in Fig.25, with the back scan current passing through the origin. These results indicates that the peak (I) must be oxidation of a soluble species at the pyrite surfaces. The back sweep current is the true current resulting from this oxidation reaction, while the difference in current between the forward and back scan is the oxidation of pyrite surface under these potentials. Figure 26 shows the dependence of peak I on the solution $\mathrm{pH}$. It can be seen that the peak 
increases significantly with increasing $\mathrm{pH}$ from 10 to 12 . Further analysis of the experimental data demonstrates that the Tafel slope of the reaction is about $120 \mathrm{mV}$, Fig.27. These results indicate that the reaction is one-electron transfer reaction controlled and involves one hydroxide ion. Thus, the following reaction is suggested for the initial oxidation of the pyrite surfaces:

Further studies demonstrate that this phenomenon can be observed on all pyrite electrodes except for PAPY and KYPY (i.e., class A), indicating that it is independent of the sources, crystal structure and semiconducting properties.

Peak II is the oxidation of the pyrite surface. Our present experimental data, however, are not sufficient to conclude the exact reaction stoichiometry. More extensive studies, particularly surface spectroscopic studies, are needed. The overall reaction of pyrite oxidation can be expressed by the following reaction is very complex. It probably consists of a number of parallel reactions including the formation of elemental sulfur, thiosulfate and sulfate. The relative proportion will depend on the electrode potential and hydrodynamic conditions.

Typical cyclic voltammograms for the class B electrodes are shown in Fig.28. No characteristic oxidation and reduction peaks are observed for these two electrode in the potential range of $-1200 \mathrm{mV}$ to $1200 \mathrm{mV}$, while the current density is much higher than that of the class A electrodes. There is no significant difference in the cyclic voltammograms in alkaline and acidic $\mathrm{pH}$ solutions. The nature of the current cannot be determined from the results obtained so far. 


\section{REFERENCES}

Ahlberg, E., Forssberg, E. and Wang, X.H., (1990), Surface oxidation of pyrite in alkaline solution, Journal of Applied Electrochemistry, Vol.20, pp1033-1039.

Bard, A. and Faulkner, L.R., (1980), Electrochemical Methods: Fundamentals and Applications. John Wiley \& Sons, 705pp.

Chander, S., (1991), paper presented at 1991 SME annual meeting, Denver, Co.

Chander, S. and Aplan, F.F., (1990), Surface and Electrochemical Studies in Coal Cleaning, Final Report, DE-FG22-85PC80523. 97pp.

Chander, S. and Briceno, A., 1987. Kinetics of pyrite oxidation. Minerals and Metallurgical Processing. pp171-176.

Diao, J.L., (1990), Coal Surface Characterization by Film Flotation, Ph.D. Thesis, University of California, Berkeley, Ca.

Fowkes, F., (1990), Quantitative characterization of the acid-base properties of solvents, polymers and inorganic surfaces. J. Adhesion Sci. Technol., 4:669-691.

Good, R. et al, (1990), Theory of the acid-base hydrogen bonding interactions, contact angle and the hydteresis of wetting: application to coal and graphite surfaces. J. Adhesion Sci. Technol., 4:607-617.

Hamilton, I.C. and Wood, R., (1981) An investigation of surface oxidation of pyrite and pyrrhotitte by linear potential sweep voltammetry. J. Electroanal. Chem., 118:327-343.

Meyer, R.E., (1979) Electrochemistry of $\mathrm{FeS}_{2}$ J. Electroanal. Chem., 101:59-71.

Wang, X.H., (1989), The chemistry of Flotation, Activation and Depression of IronContaining Sulfide Minerals. Ph.D. Thesis, Lulea University, Sweden. 514pp.

Wang, X.H., (1991a), A method of studying the surface energetics of high energy solids. To be submitted for J. Colloid Interface Science for publication.

Wang, X.H., (1991b), Thermodynamic relationships between the interfacial tension, contact angle and surface potential. Part I. To be submitted for J. Colloid Interface Sci. for publication.

Wang, X.H. and Forssberg, (1990) EDTA Induced flotation of sulfide minerals. Journal of 
Colloid and Interíace Science, Vol.140, pp217-226.

Wang, X.H., Leonard, J.W. and Parekh, B.K., (1990), Pyrite surface characterization and conirol for advaniced coal desulfurization technologies. First Quarterly Technical report, DE-FG22-90PC90295.

Wang, X.H., Leonard, J.W. and Parekh, B.K., (1991), Pyrite surface characterization and control for advanced coal desulfurization technologies. Second Quarterly Technical report, DE-FG22-90PC90295.

Wang, X.H., L.eonard, J.W., Parekh, B.K., Raichur, A.M. and Jiang, C., (1991), Pyrite surface characterization and control for advanced coal desulfurization technologies. Third Quarterly Technical report, DE-FG22-90PC90295.

Wang, X.H., Leonard, J.W., Parekh, B.K., Jiang, C. and Raichur, A.M., (1991), Pyrite surface characterization and control for advanced coal desulfurization technologies. Fourth Quarterly Technical report, DE-FG22-90PC90295.

Wang, X.H. and Parekh, B.K., (1991), Characterization of chemical and energetic compositions of fine coal surfaces: advances and problems. In Pittsburgh 8th International Conference, Oct., 1991. 


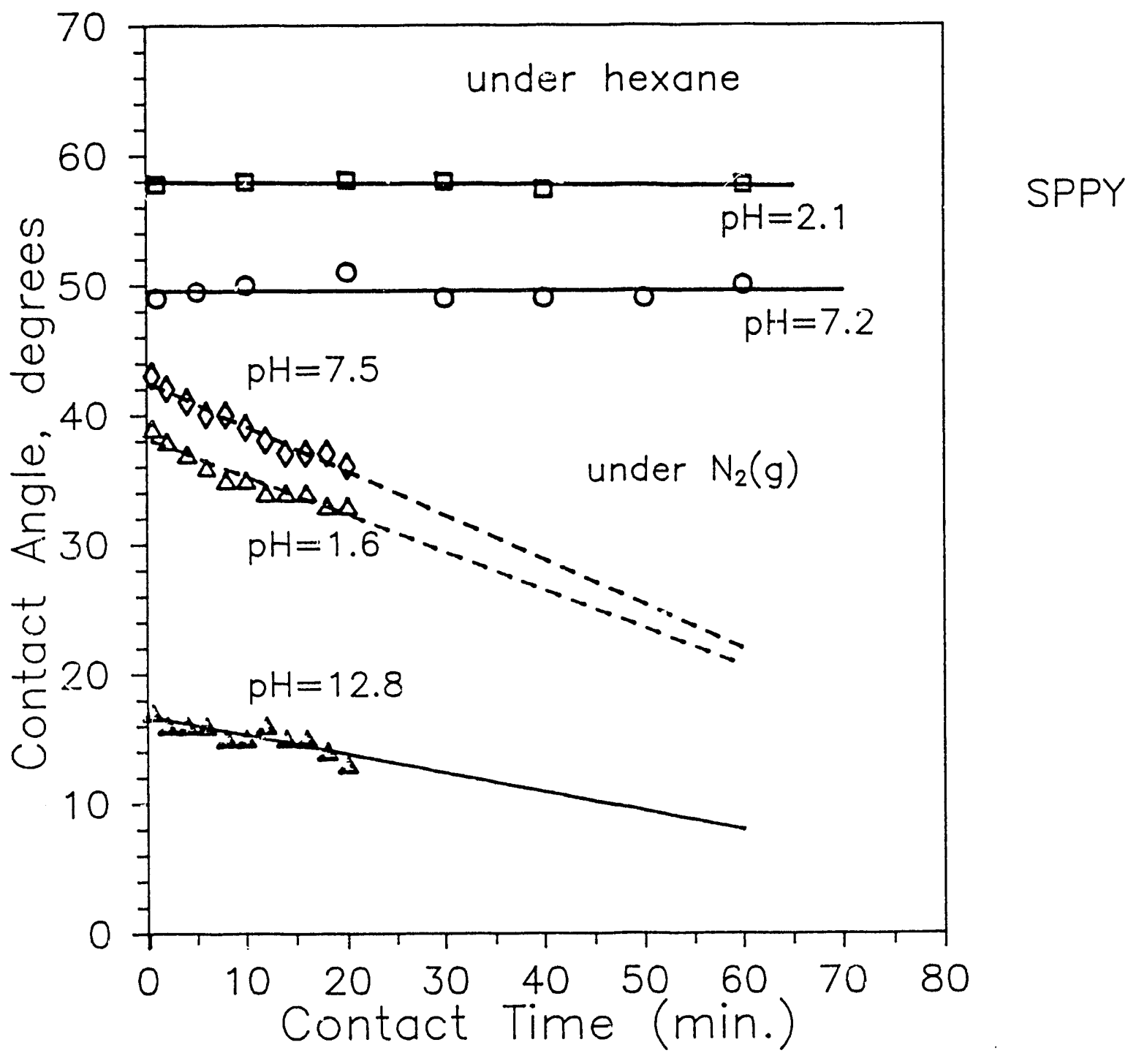

Fig.1 Apparent contact angle of water droplet of different $\mathrm{pH}$ values on SPPY surfaces as a function of contact time under different environment. 


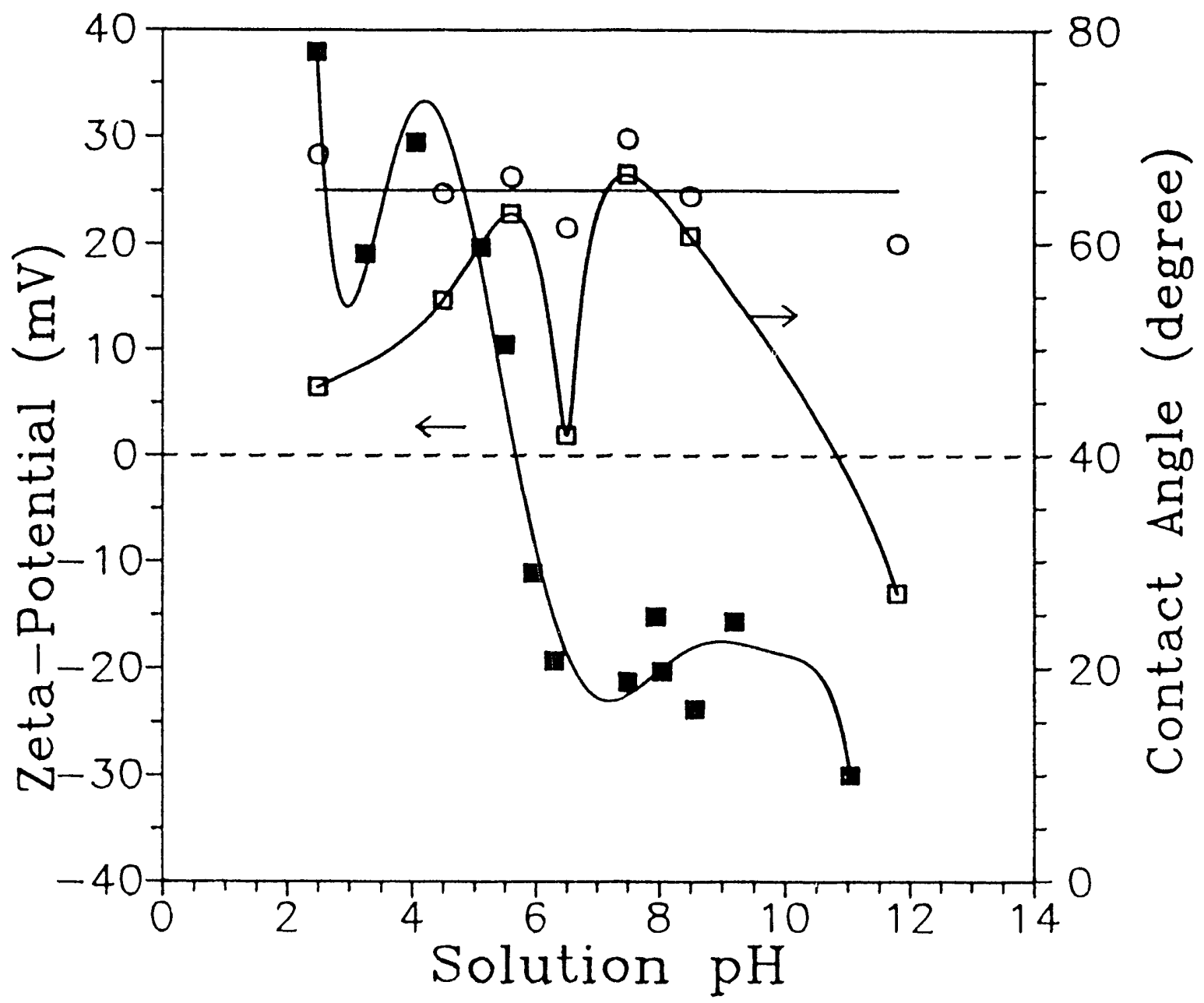

Fig.2 Contact angle of water droplets on ICPY surfaces and zeta-potential as a function of solution $\mathrm{pH}$. Contact angles of "fresh" surfaces were obtained by extrapolating to zero contact angle. 


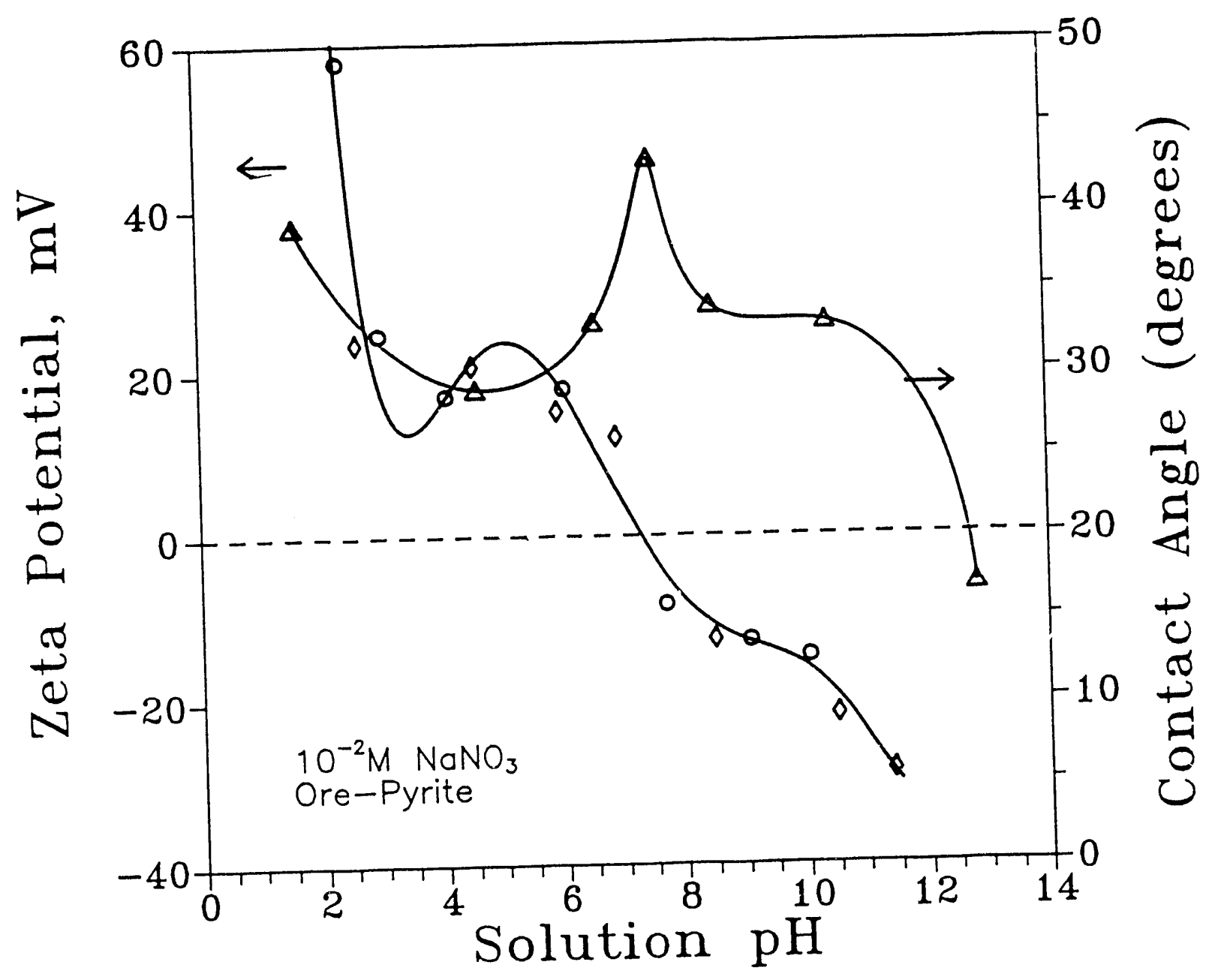

Fig.3 Contact angle and zeta-potential of SPPY as a function of $\mathrm{pH}$ 


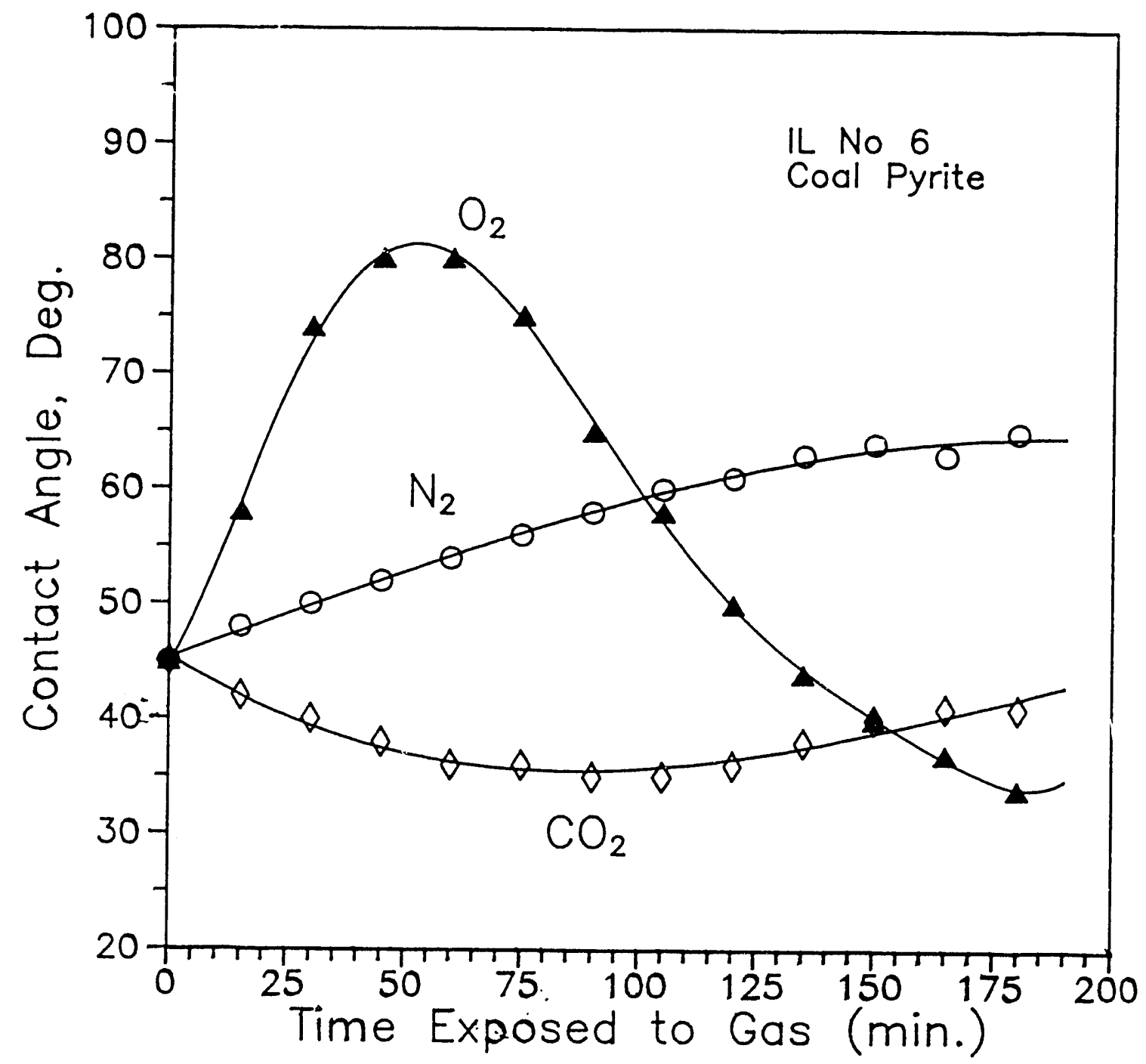

Fig.4 Contact angle of water droplets on ICPY as a function of the time of the surface immersed into the solutions saturated with nitrogen, oxygen and carbon dioxide. 


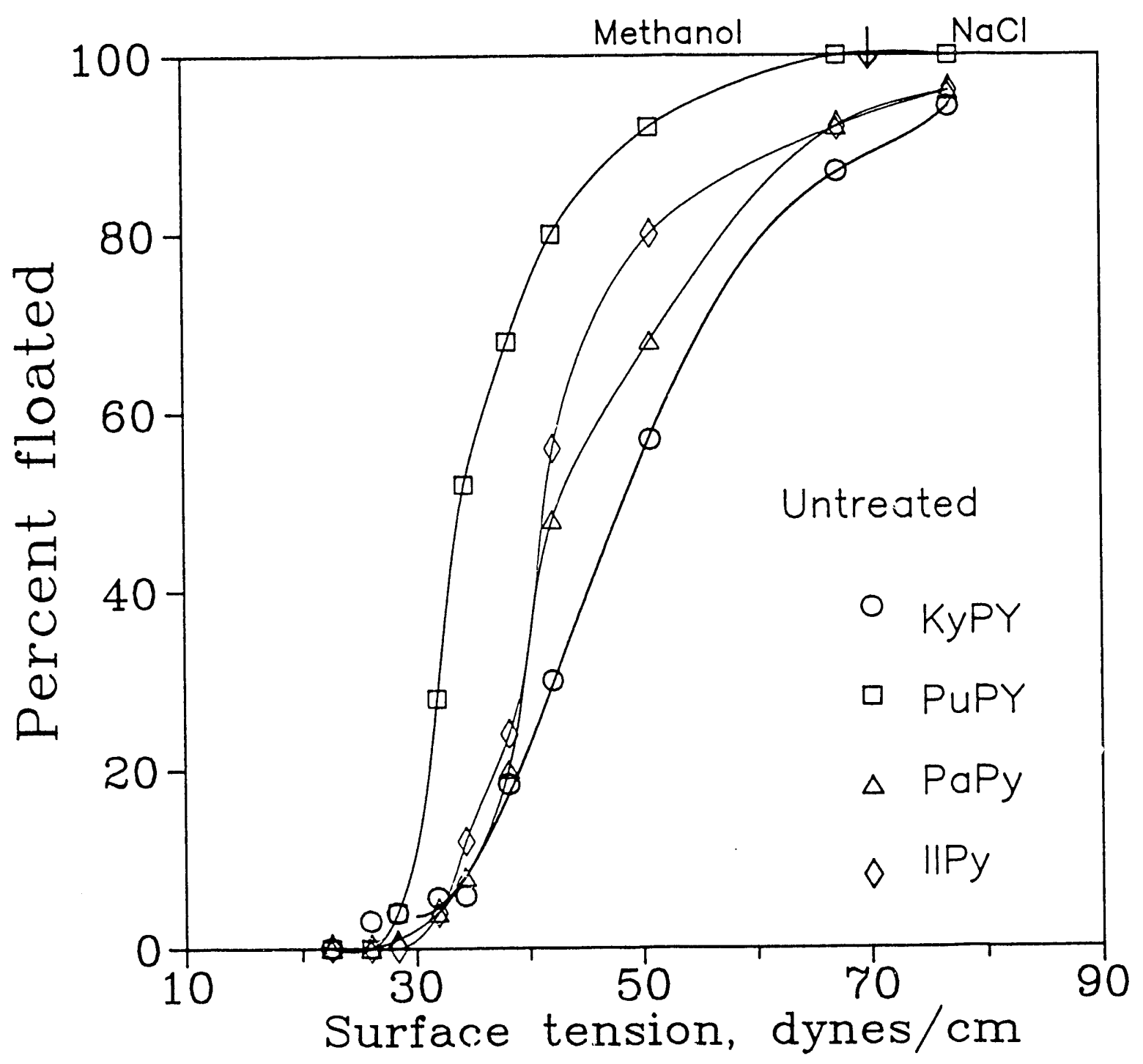

Fig.5 Flotation percentage as a function of surface tension of aquatic methanol solution for pyrite from different sources. 


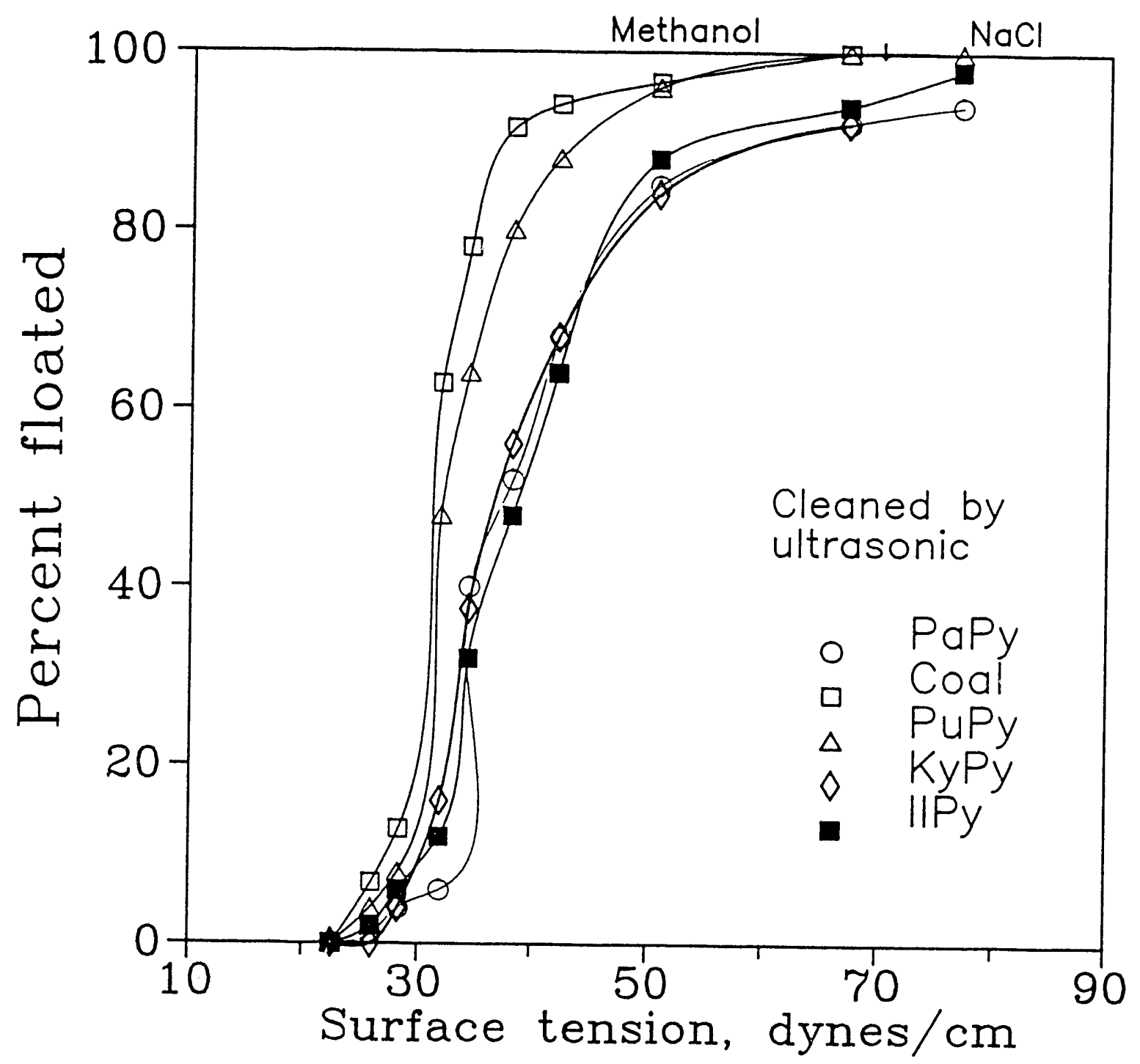

Fig.6 Flotation percentage as a function of surface tension of aquatic methanol solution for pyrite from different sources after surface cleaning by ultrasonication. 


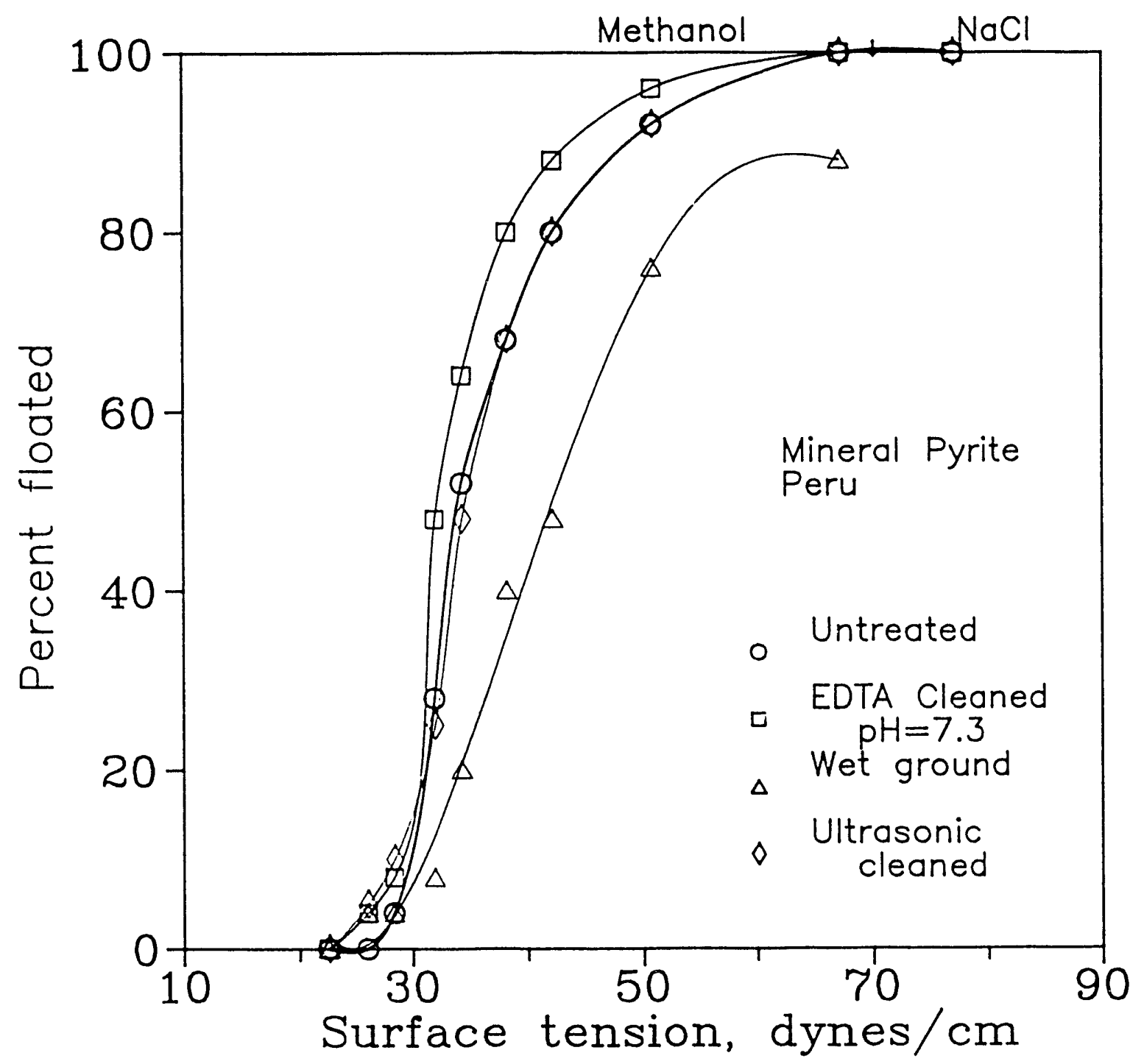

Fig.7 Flotation percentage of ore-pyrite PUPY as a function of surface tension of aquatic methanol solution after different chemical and mechanical treatment. 


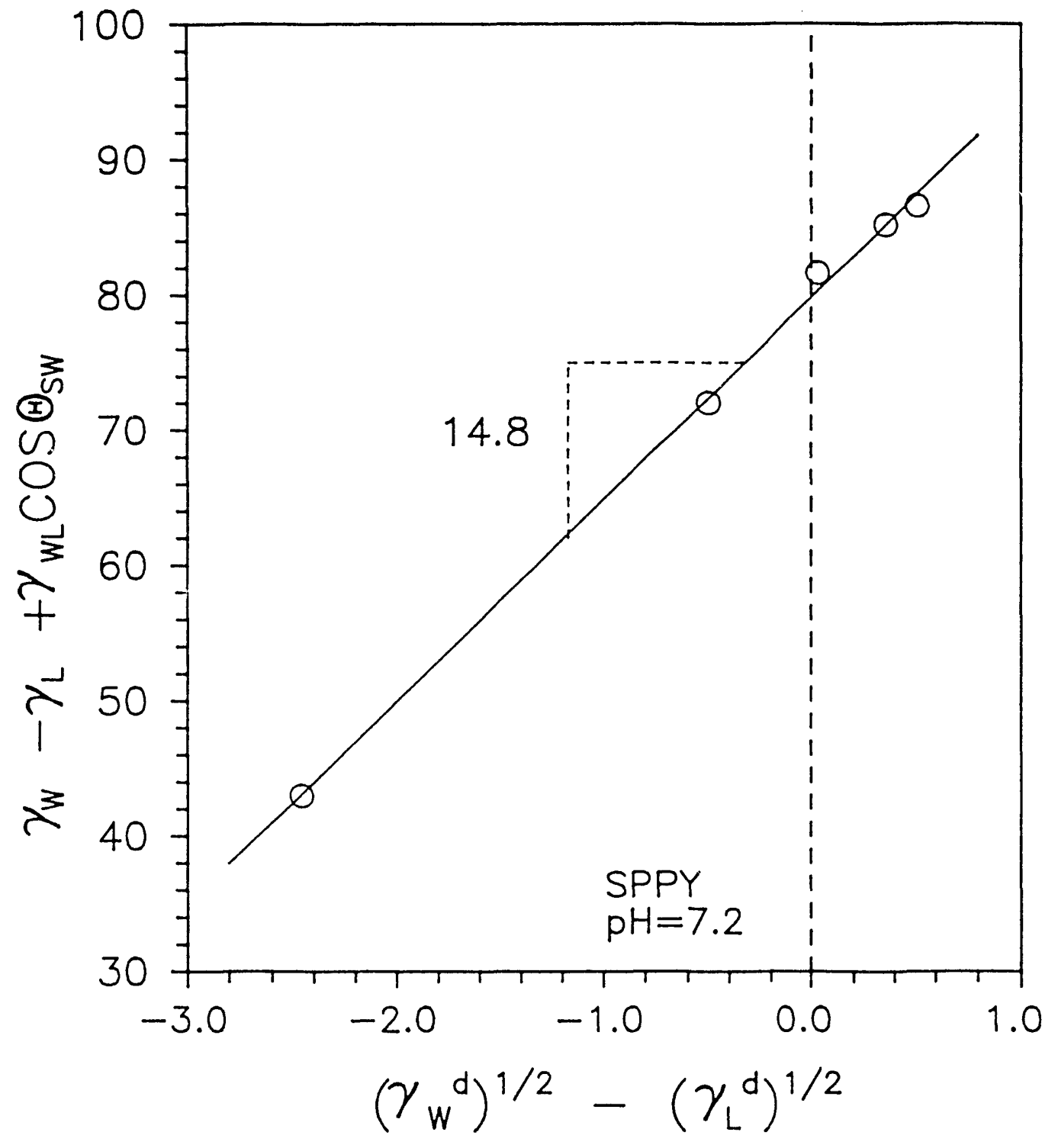

Fig.8 Plot of $\gamma_{w}-\gamma_{L}+\gamma_{w L} \cos \theta$ against $\left[\left(\gamma_{w}{ }^{0}\right)^{0.5}-\left(\gamma_{L}{ }^{d}\right)^{0.5}\right]$ for ore-pyrite (SPPY). Contact angles of water droplet under $n$-alkane. 


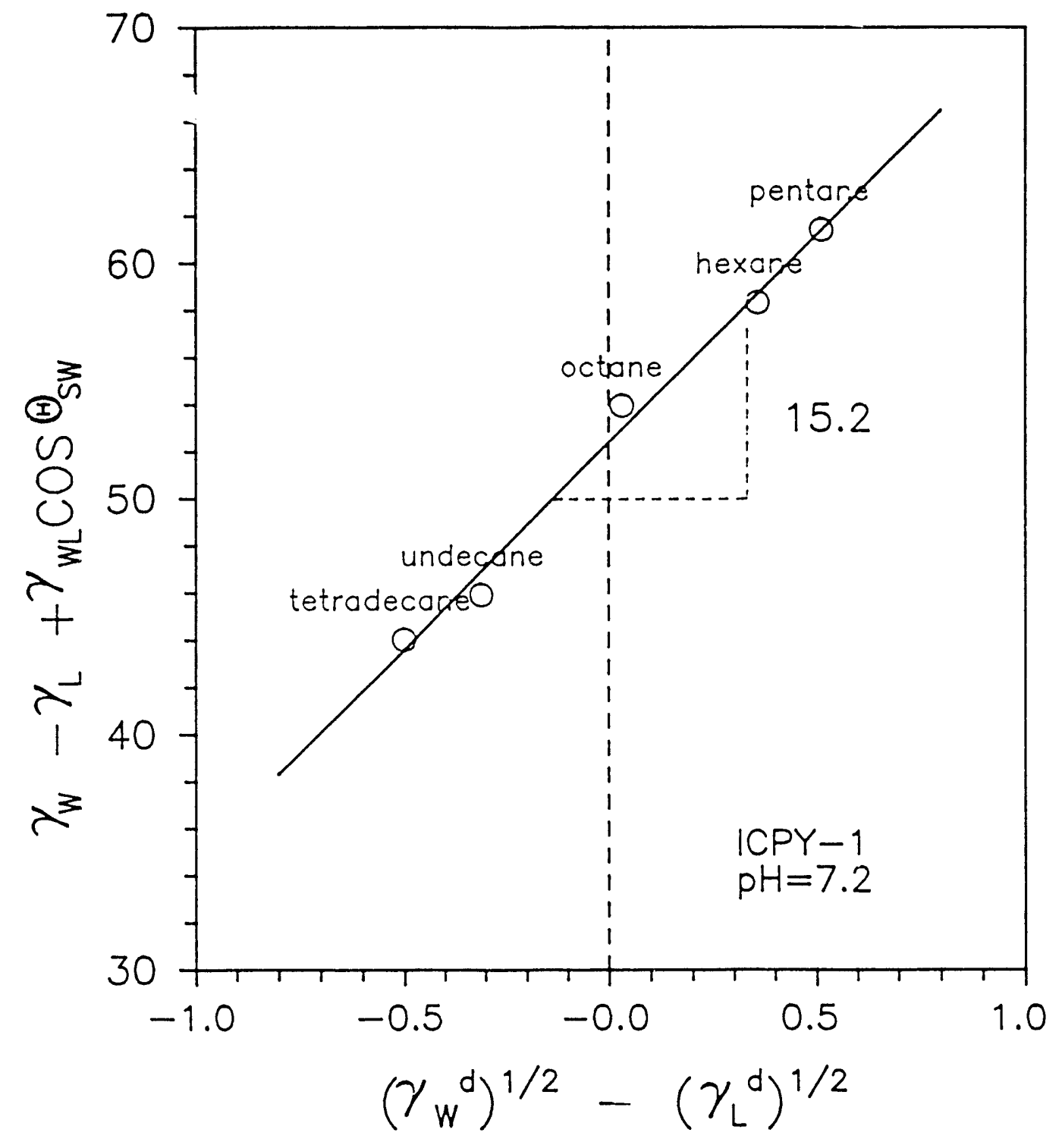

Fig.9 Plot of $\gamma_{w}-\gamma_{L}+\gamma_{W L} \cos \theta$ against $\left[\left(\gamma_{w}{ }^{d}\right)^{0.5}-\left(\gamma_{L}{ }^{d}\right)^{0.5}\right]$ for Coal-pyrite (ICPY). Contact angles of water droplet under $n$-alkane. 


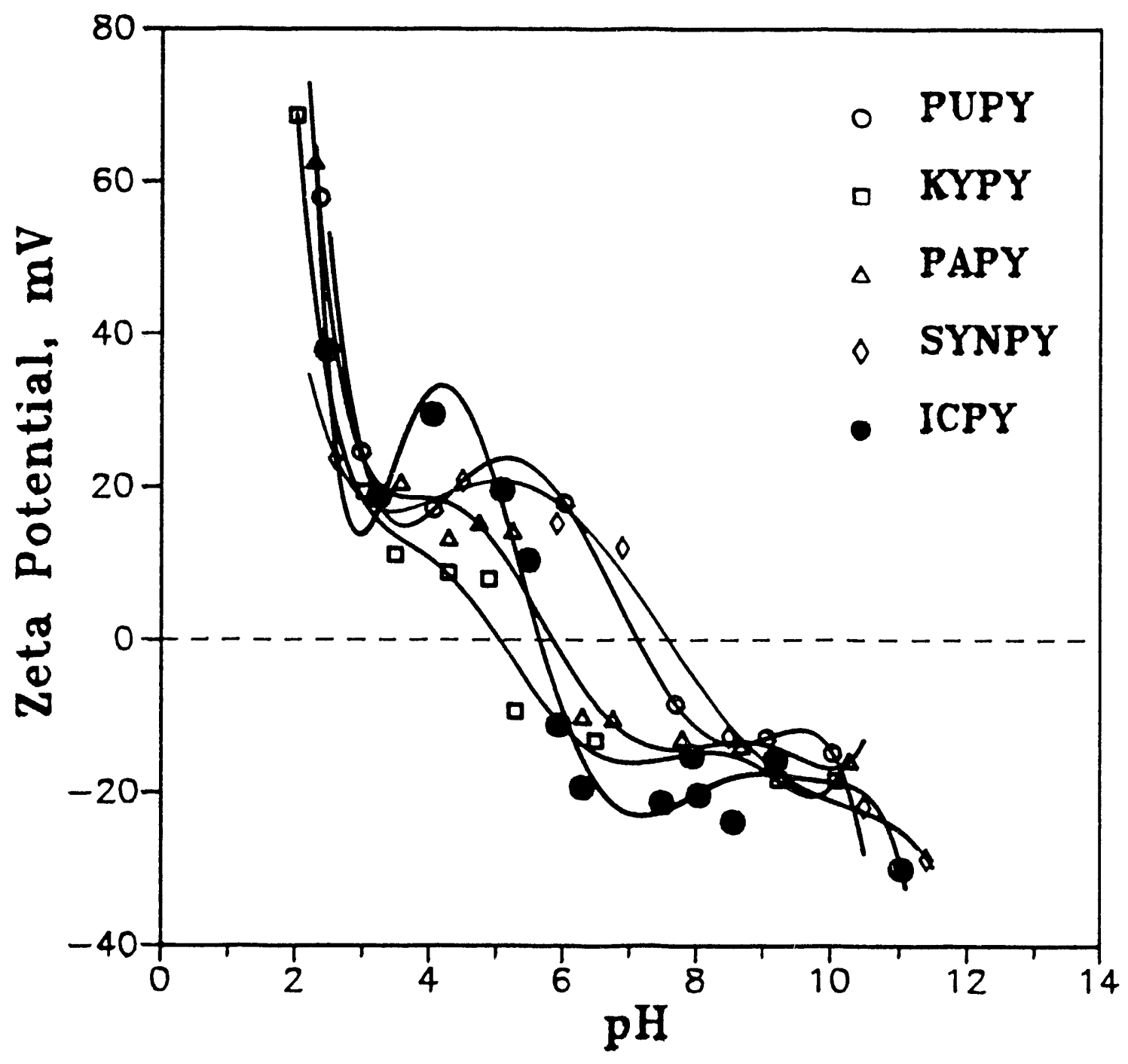

Fig.10 Zeta-potential of various coal- and ore-pyrite samples as a function of solution $\mathrm{pH}$. 


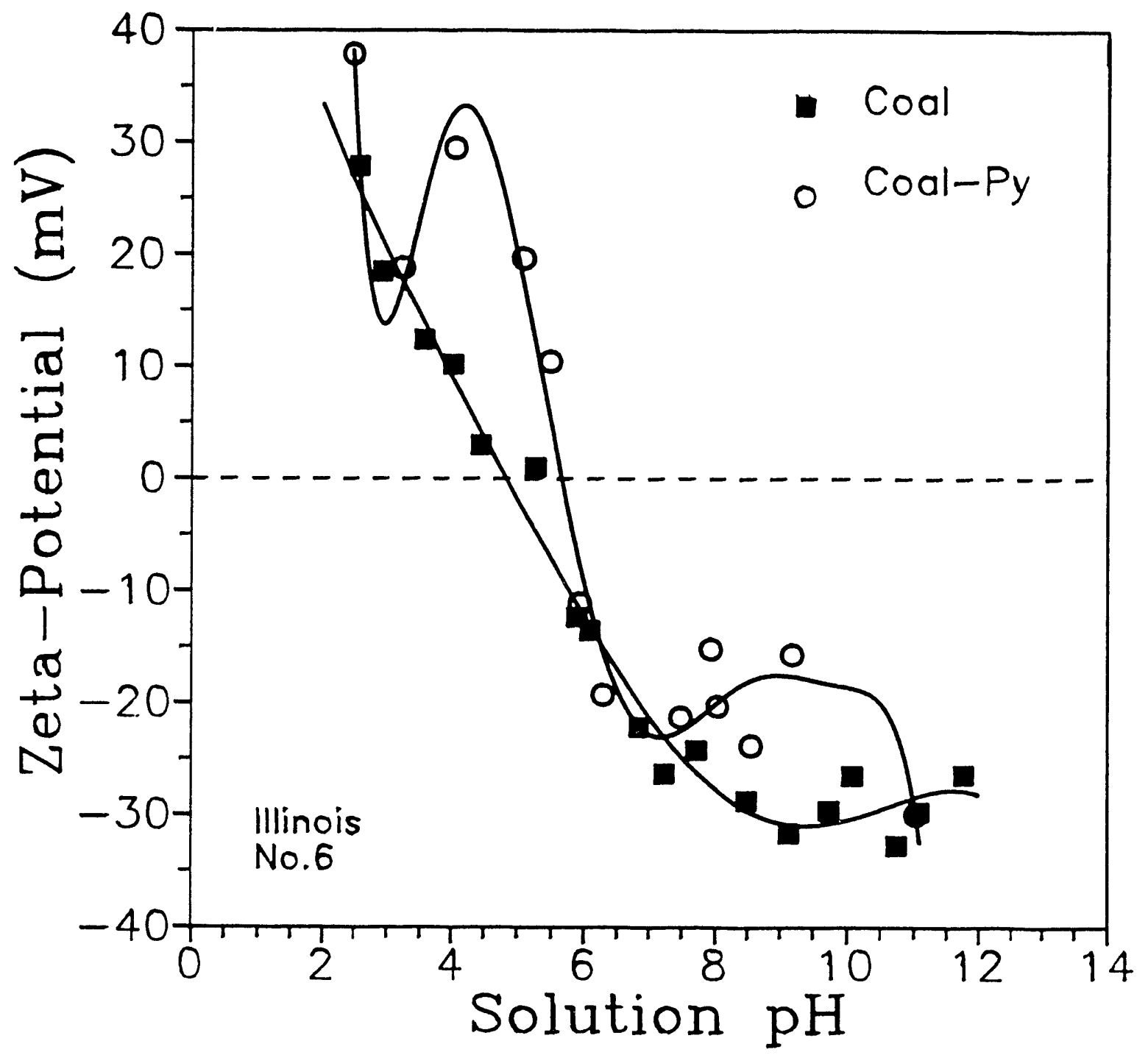

Fig.11 Comparison of zeta-potential of coal-pyrite (ICPY) with Illinois No.6 coal. 


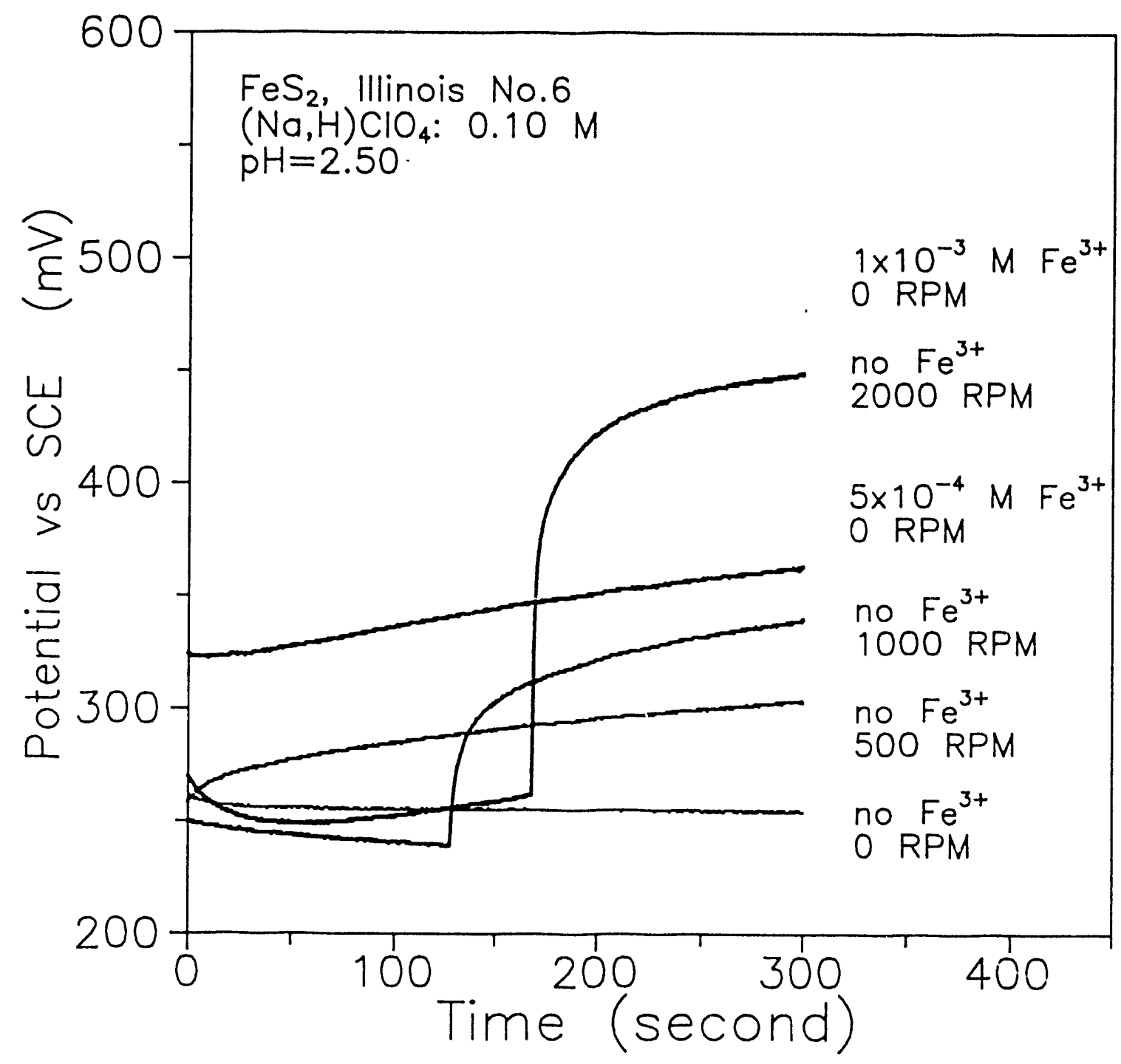

Fig.12 Open-circuit potential of ICPY electrode as a function of time under various chemical and hydrodynamic conditions at $\mathrm{pH}=2.5$. 


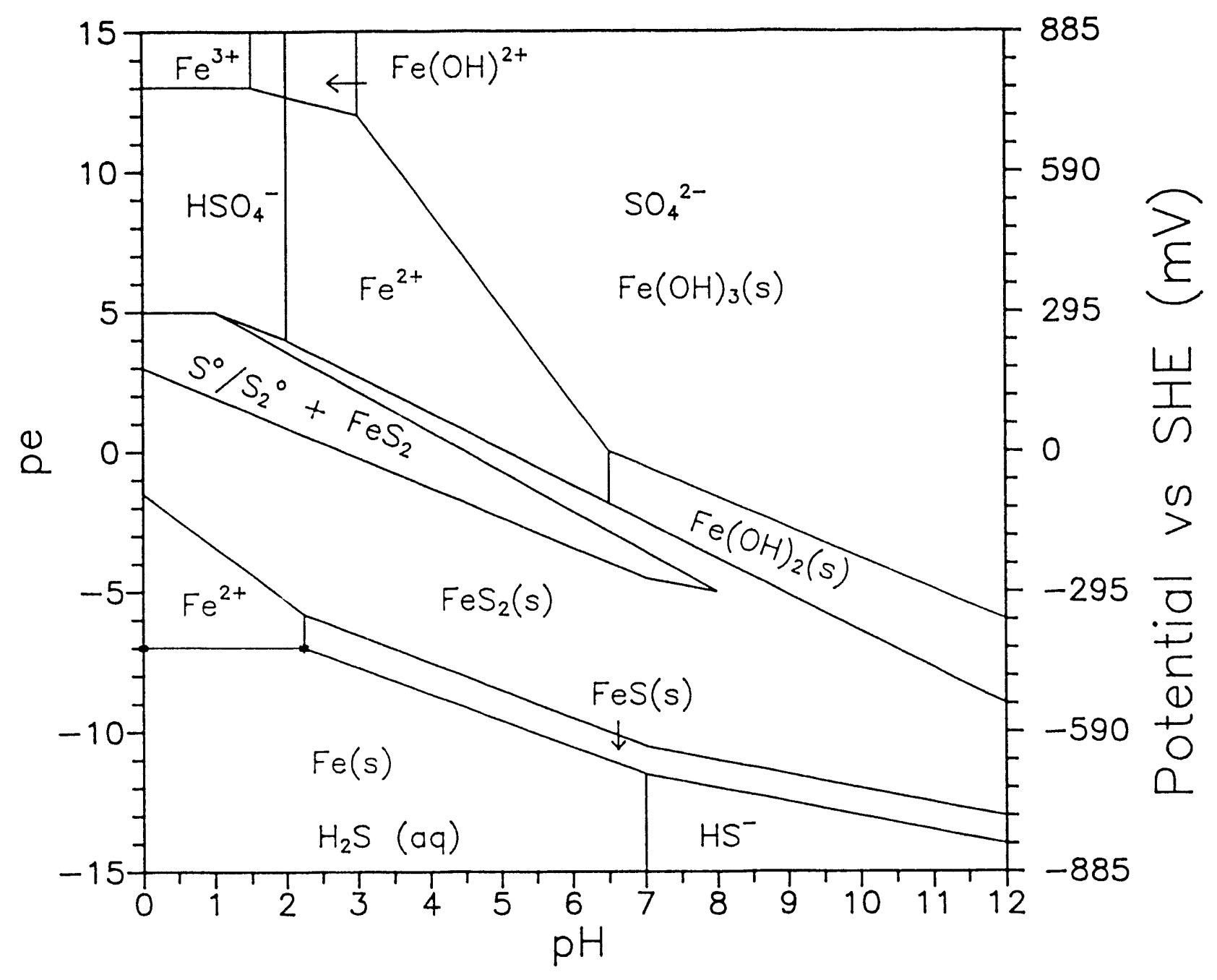

Fig. 13 Eh-pH stability diagram for the iron-sulfur-water system at total concentrations of $[\mathrm{Fe}]=[\mathrm{S}]=1.0^{*} 10^{-3} \mathrm{M}$. 


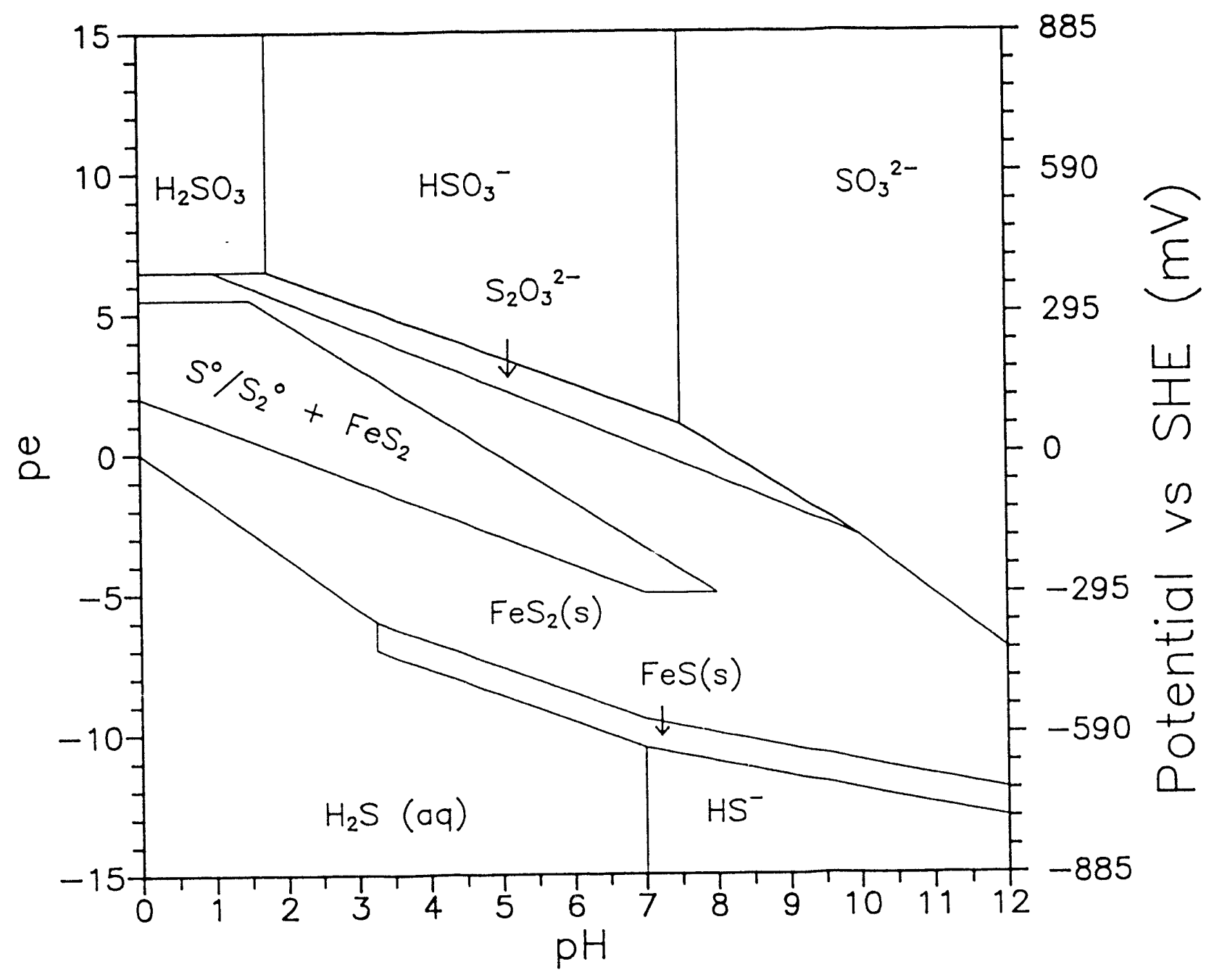

Fig.14 Eh-pH stability diagram for the iron-sulfur-water system at total concentrations $[\mathrm{Fe}]=[\mathrm{S}]=1.0^{*} 10^{-3} \mathrm{M}$, metastable sulfite is considered as the "final" oxidation product, i.e., species with oxidation state higher than S(IV) are excluded. 


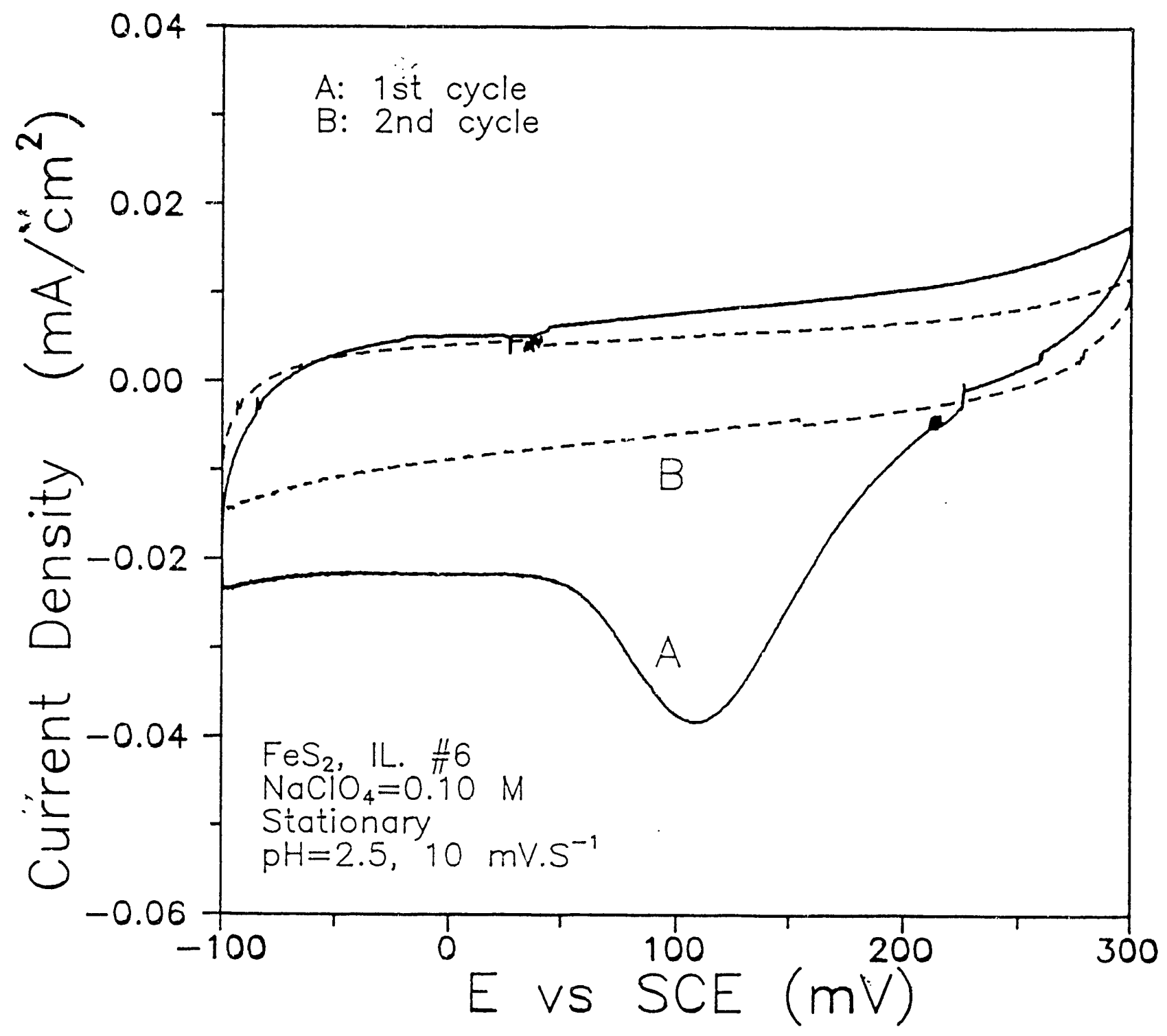

Fig. 15 Multiple cyclic voltammograms of the stationary ICPY electrode at $\mathrm{pH}=2.5$. Initial sweep started from $\mathrm{OCP}$ in negative-going direction. Solid line: first cycle; dotted line: 2nd cycle. 


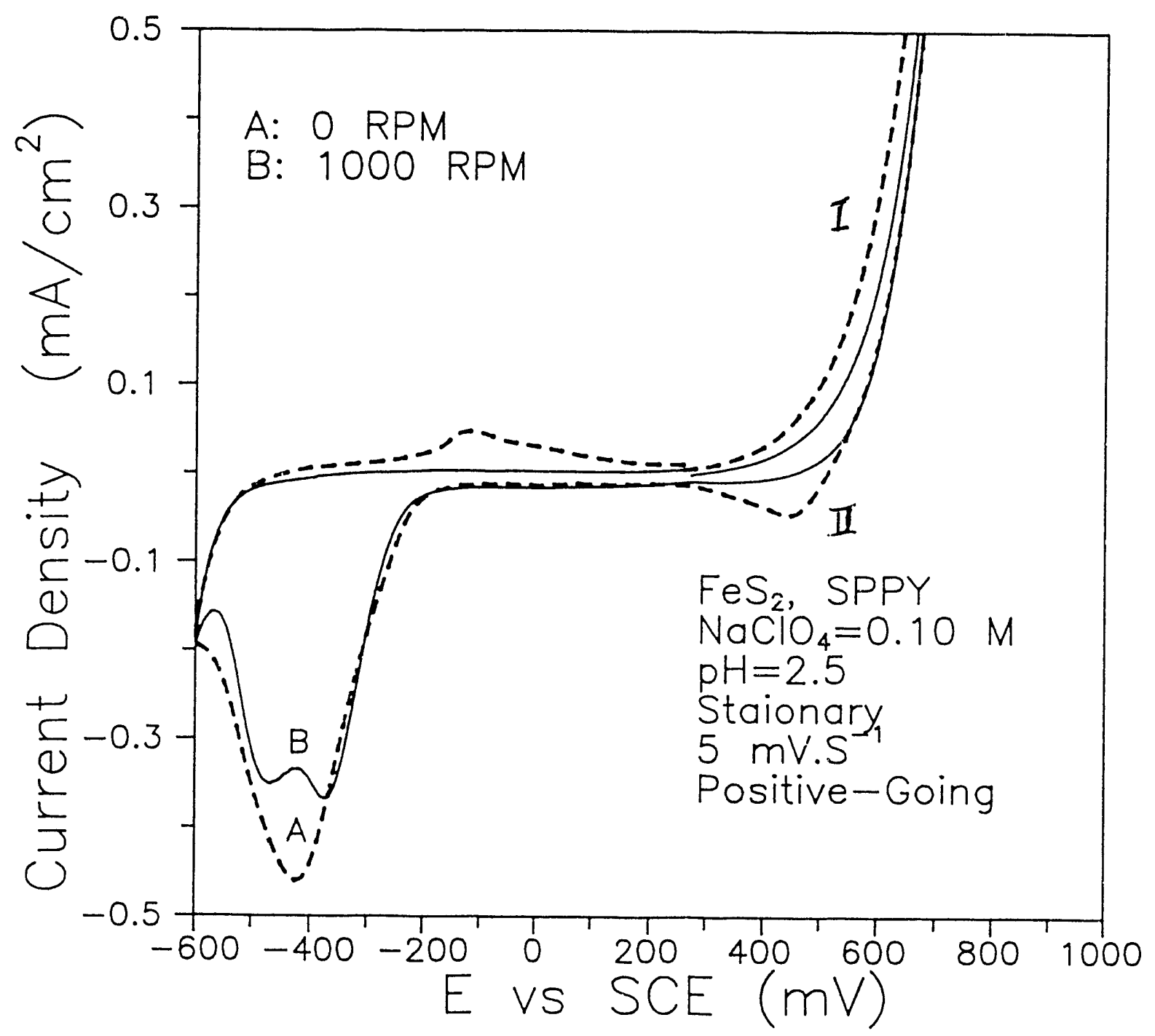

Fig.16 Cyclic voltammograms of the stationary and rotating ICPY electrode at $\mathrm{pH}=2.5$. Initial sweep started at OCP in the positive-going direction.

Sweep rate: $5 \mathrm{mV} / \mathrm{s}$. Dotted line: siationary; solid line: rotation at $1000 \mathrm{RPM}$. 


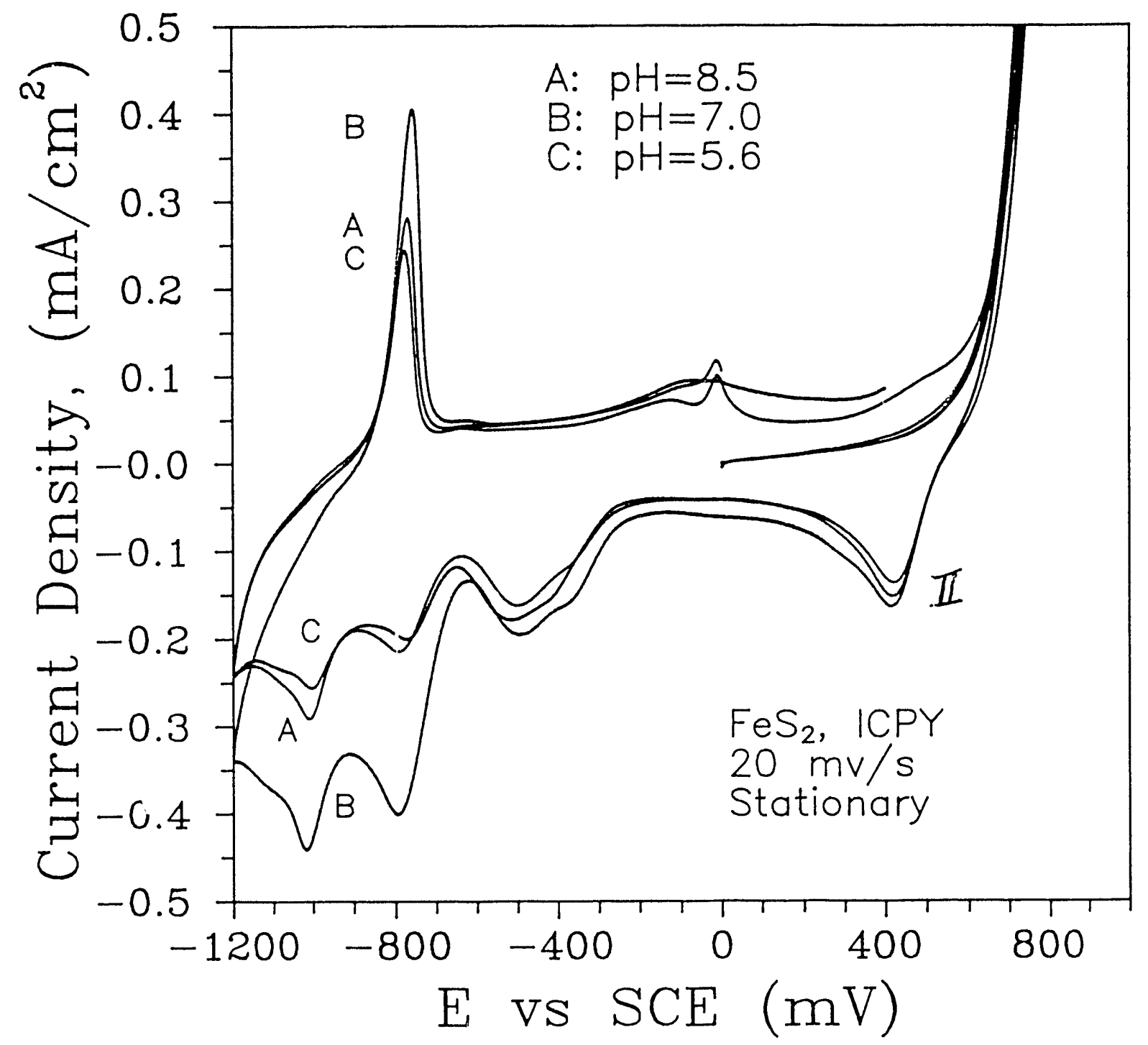

Fig.17 Cyclic voltammograms of the stationary ICPY electrode in different pH solutions. Sweep rate: $20 \mathrm{mV} / \mathrm{s}$. Initial sweep started from $O C P$ in positive-going direction. 


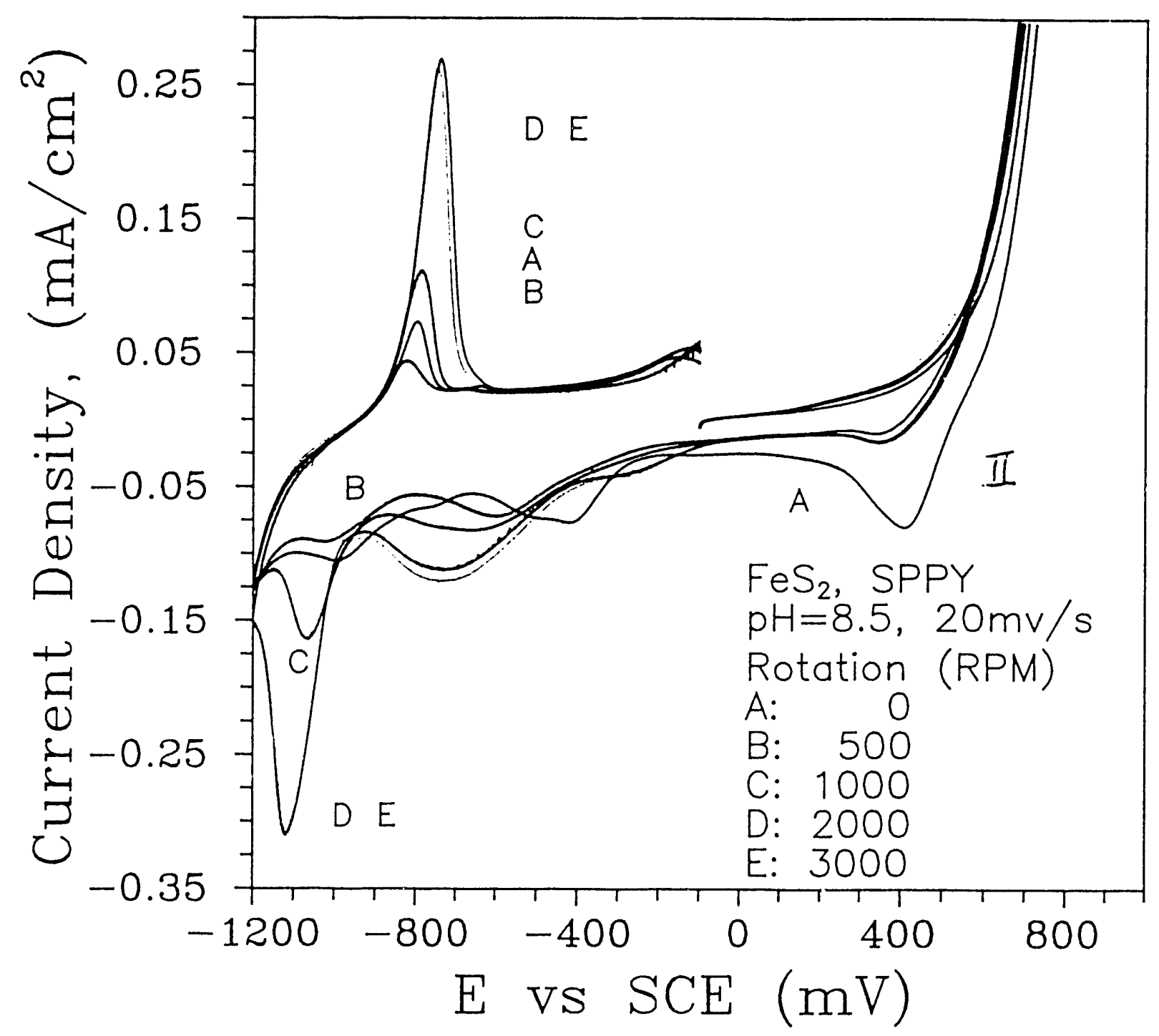

Fig.18 Cyclic voitammograms of the SPPY electrode at diferent rotation speed. Solution $\mathrm{pH}=8.5$, sweep rate $=20 \mathrm{mV} / \mathrm{s}$. 


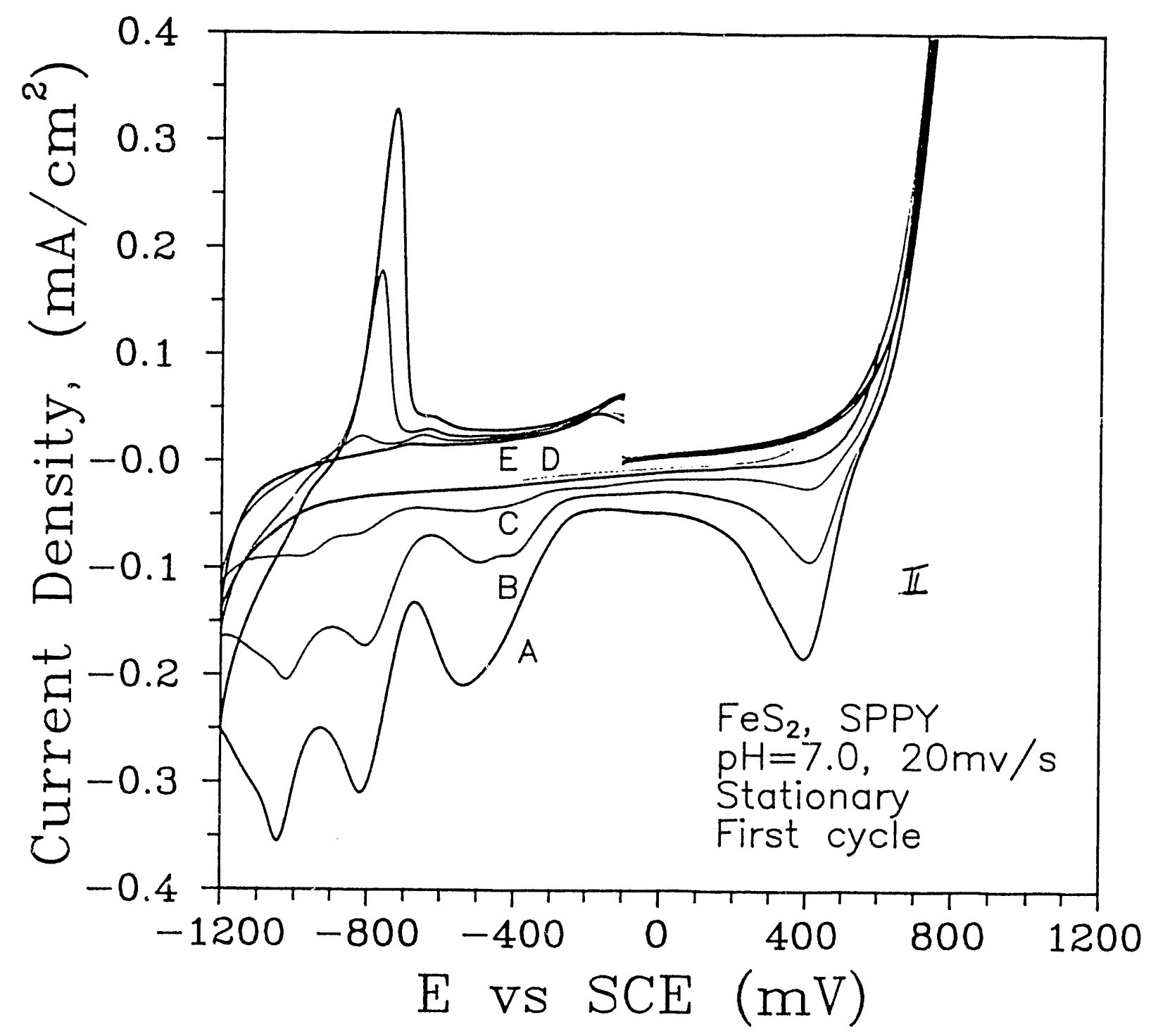

PPL $(\mathrm{mV}$ )

A: 1200

B: 1000

C: 800

D: 600

E: 400

Fig.19 Cyclic voltammograms of the stationary SPPY electrode at different positive potential limits at $\mathrm{pH}=7.0$. First potential sweep started at OCP in positive-going direction. Sweep rate: $20 \mathrm{mV} / \mathrm{s}$. 


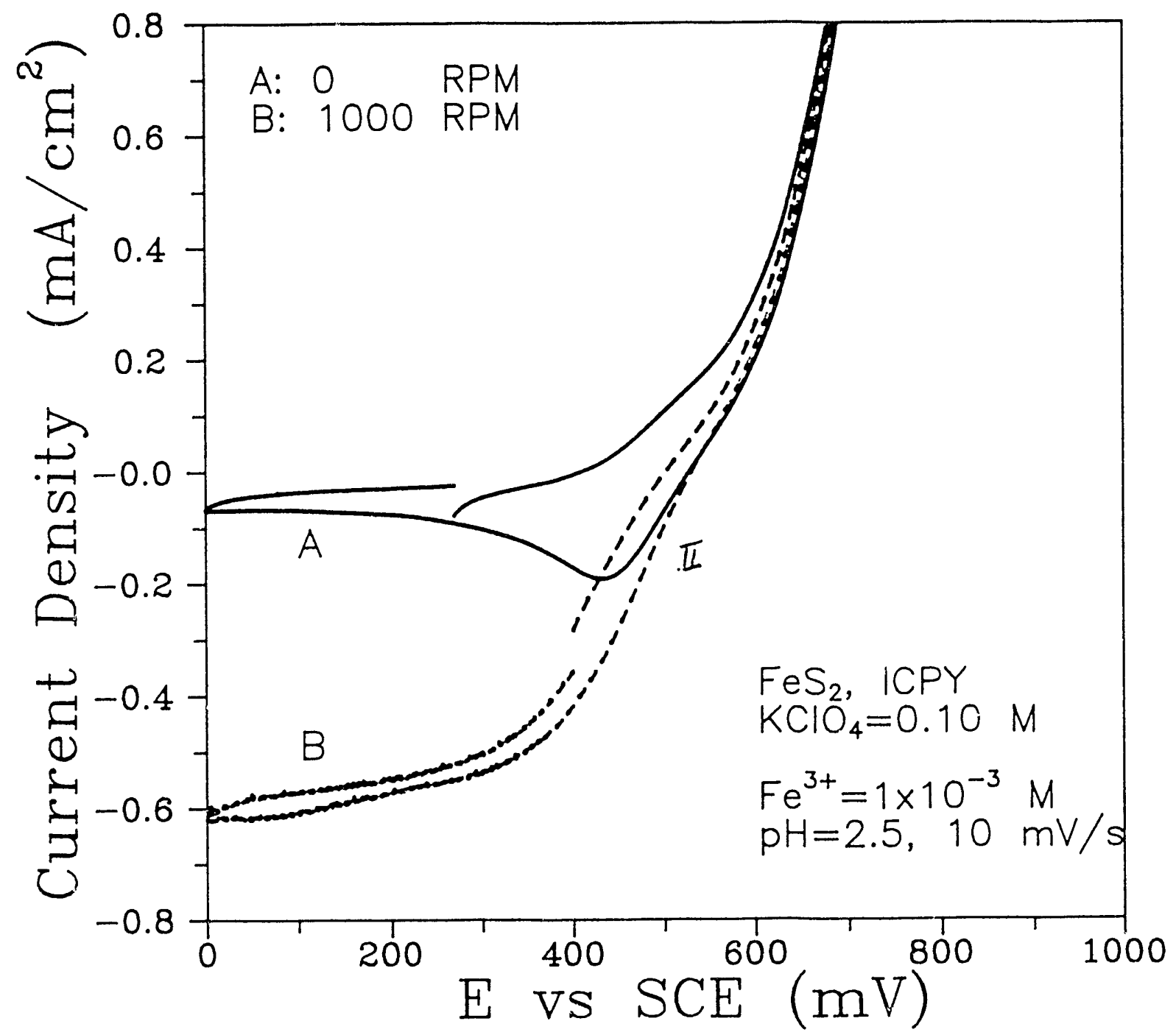

Fig.20 Cyclic voltammograms of the ICPY electrode in the presence of $1.0 \times 10^{-3} \mathrm{M}$ ferric ions and at $\mathrm{pH}=2.5$. Solid line: stationary electrode; dotted line: rotation at 1000 RPM. 


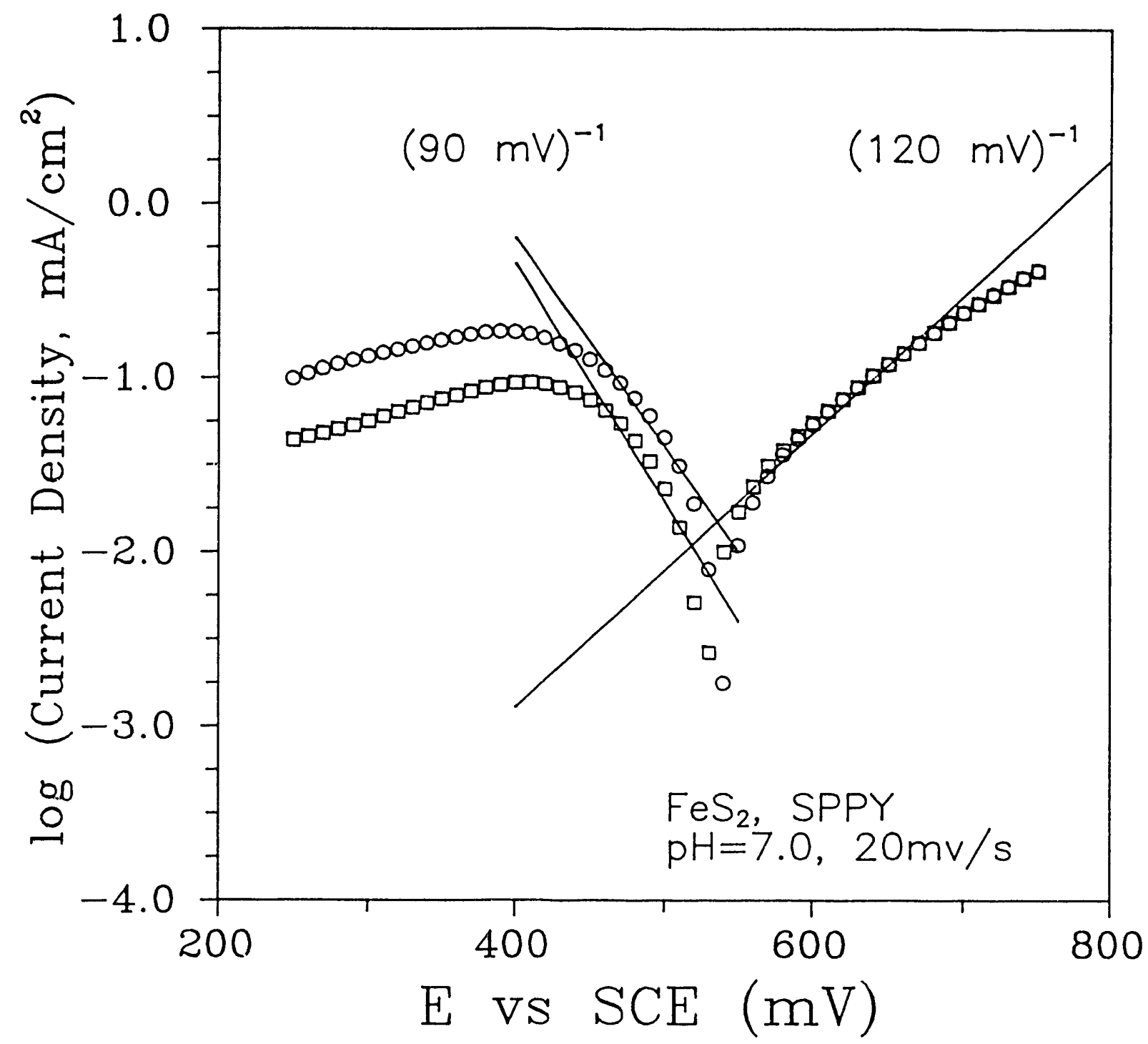

Fig. 21 Tafel plot of peak II for the SPPY electrode at $\mathrm{pH}=7$.

The Tafel slope is $70-90 \mathrm{mV}$, depending the chemical conditions in the solution. 


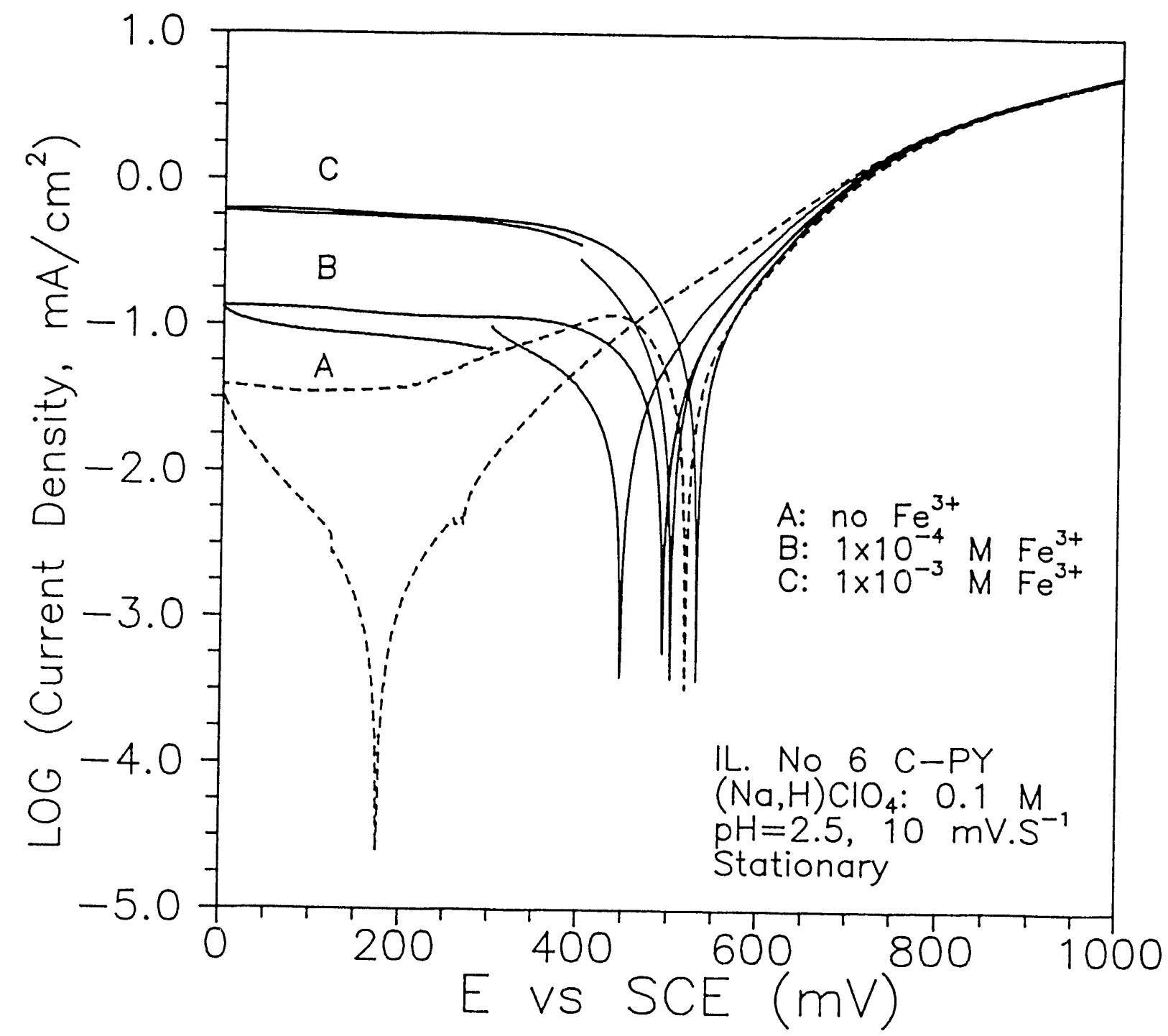

Fig.22 Tafel plots of oxidation processes of the ICPY electrode at $\mathrm{pH}=2.5$ in the presence of different concentrations of ferric ions. 


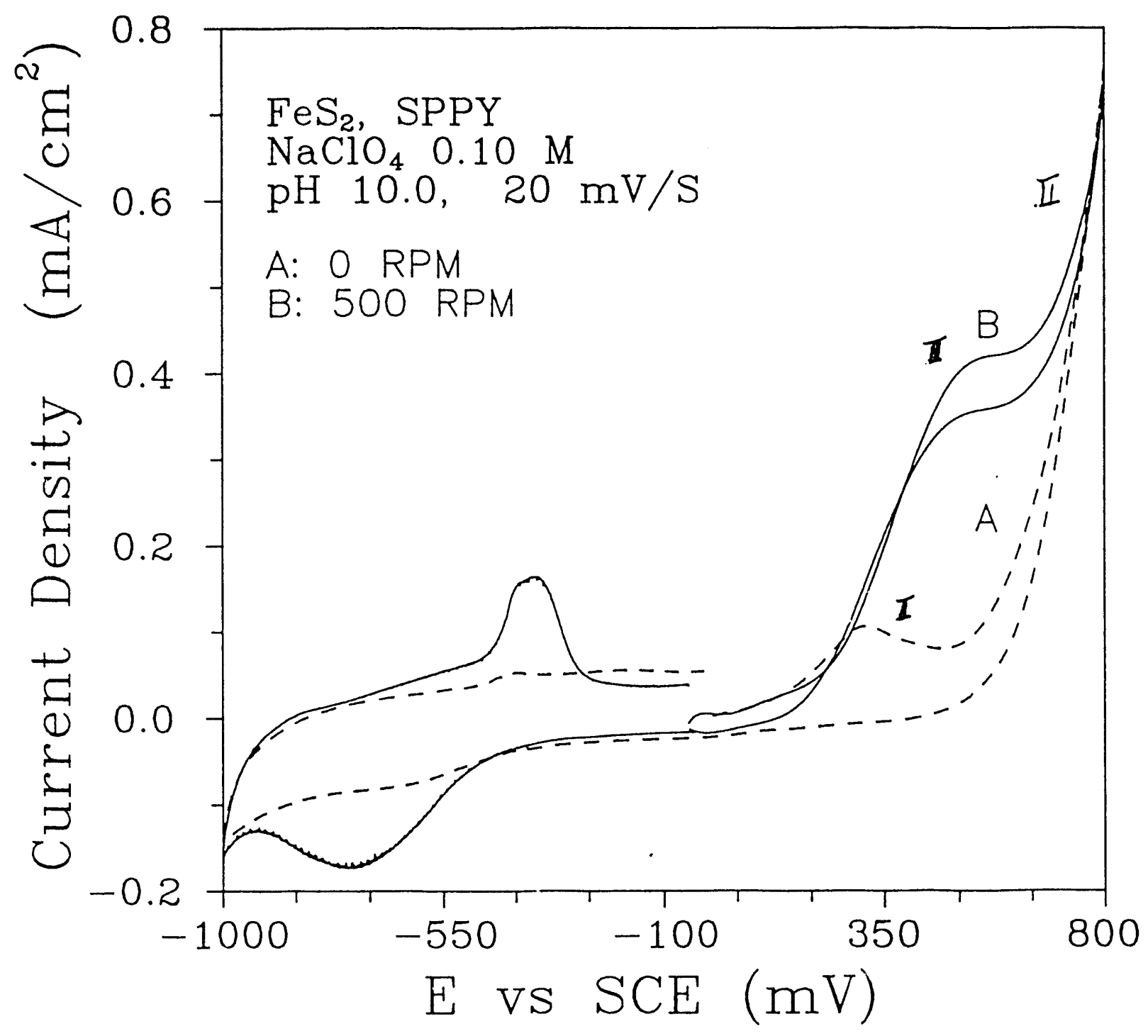

Fig. 23 Cyclic voltammograms of the SPPY electrode at $\mathrm{pH}=10.0$. Initial sweep started from OCP in the positive-going direction. Dotted line: stationary. Solid line: Rotation at 500 RPM. 


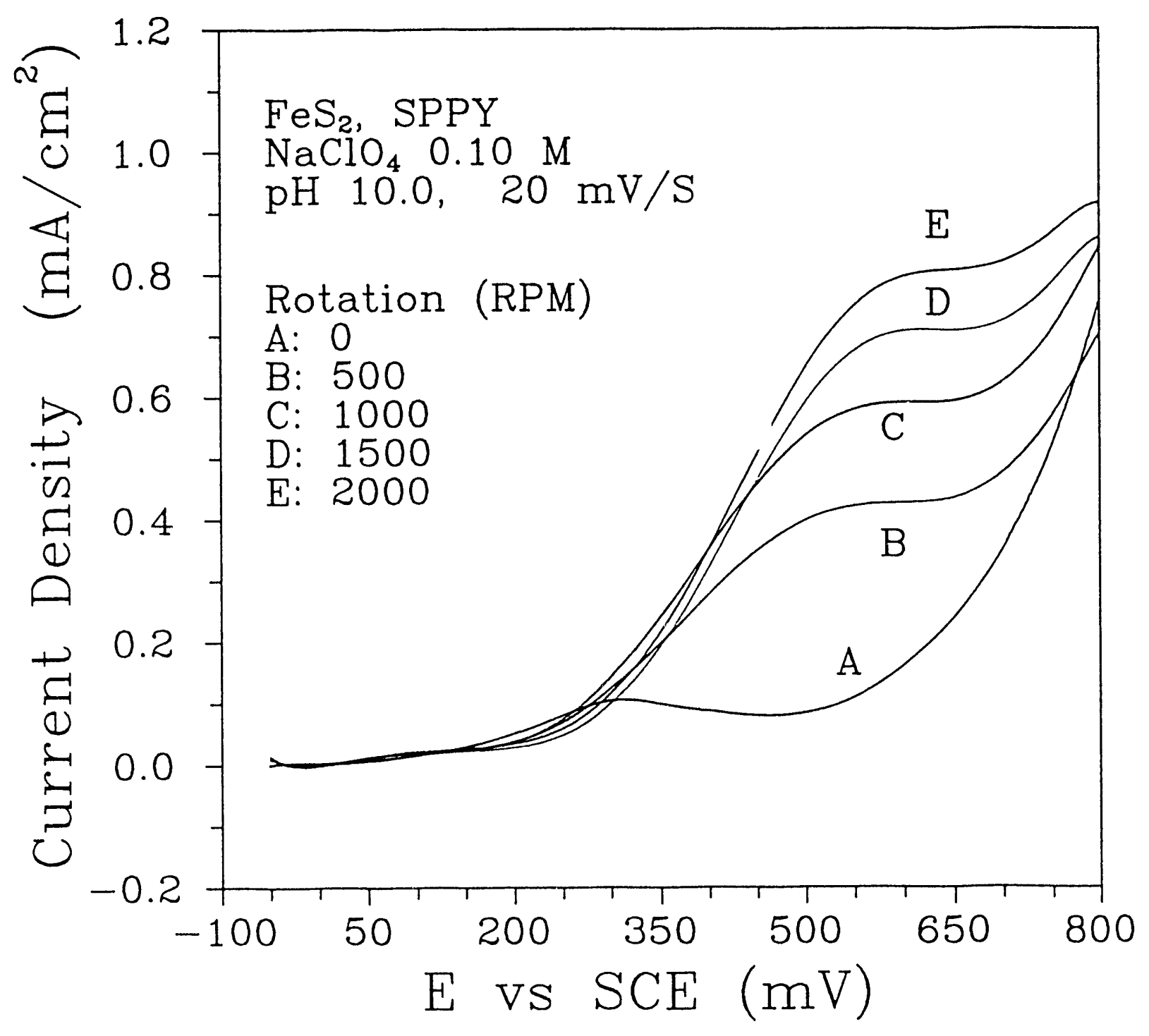

Fig.24 Linear potential sweep voltammograms of the SPPY electrode at $\mathrm{pH}=10.0$ and at different rotation speeds. 


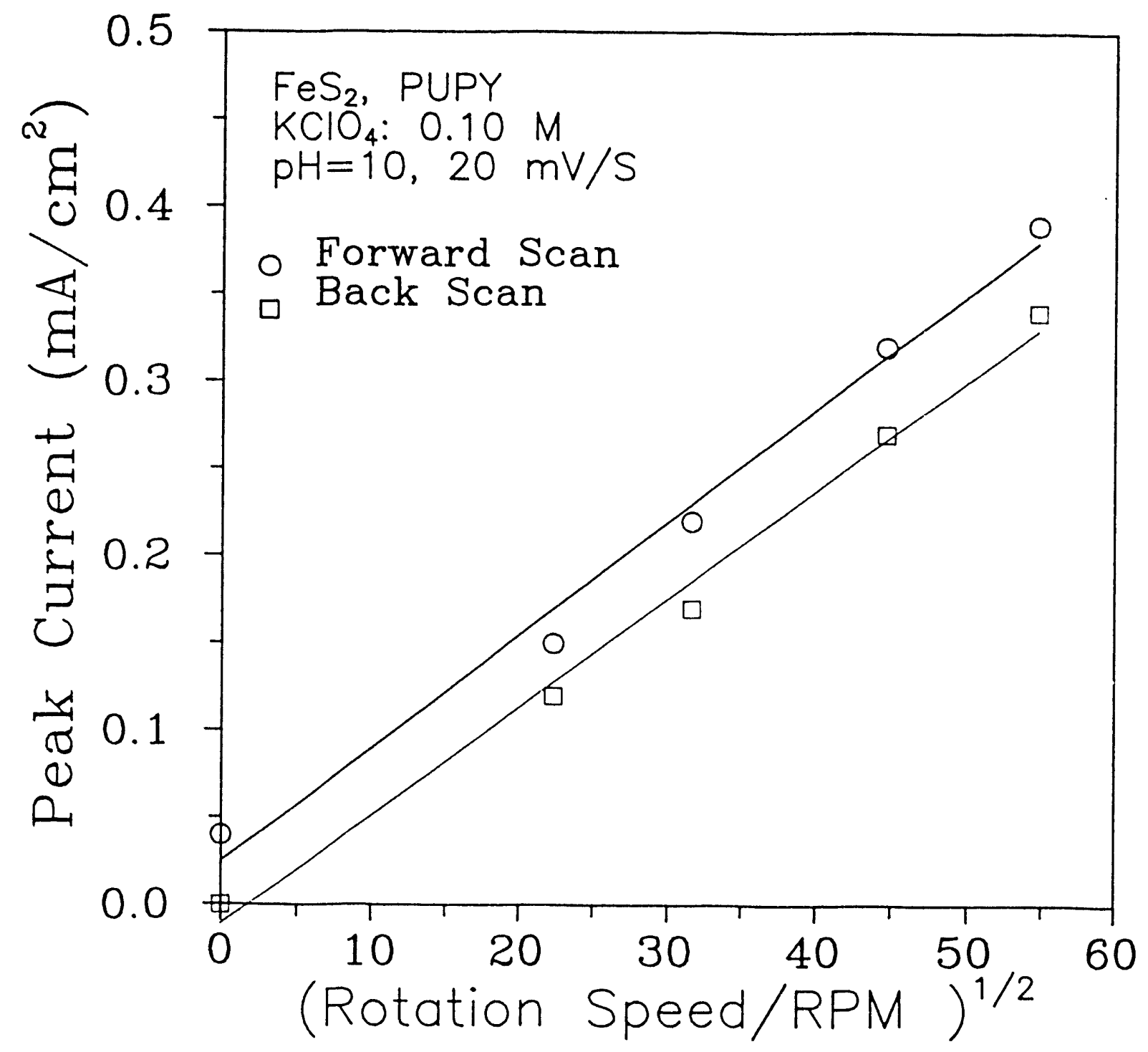

Fig.25 Limiting current as a function of square root of the rotation speed for the PUPY electrode. 


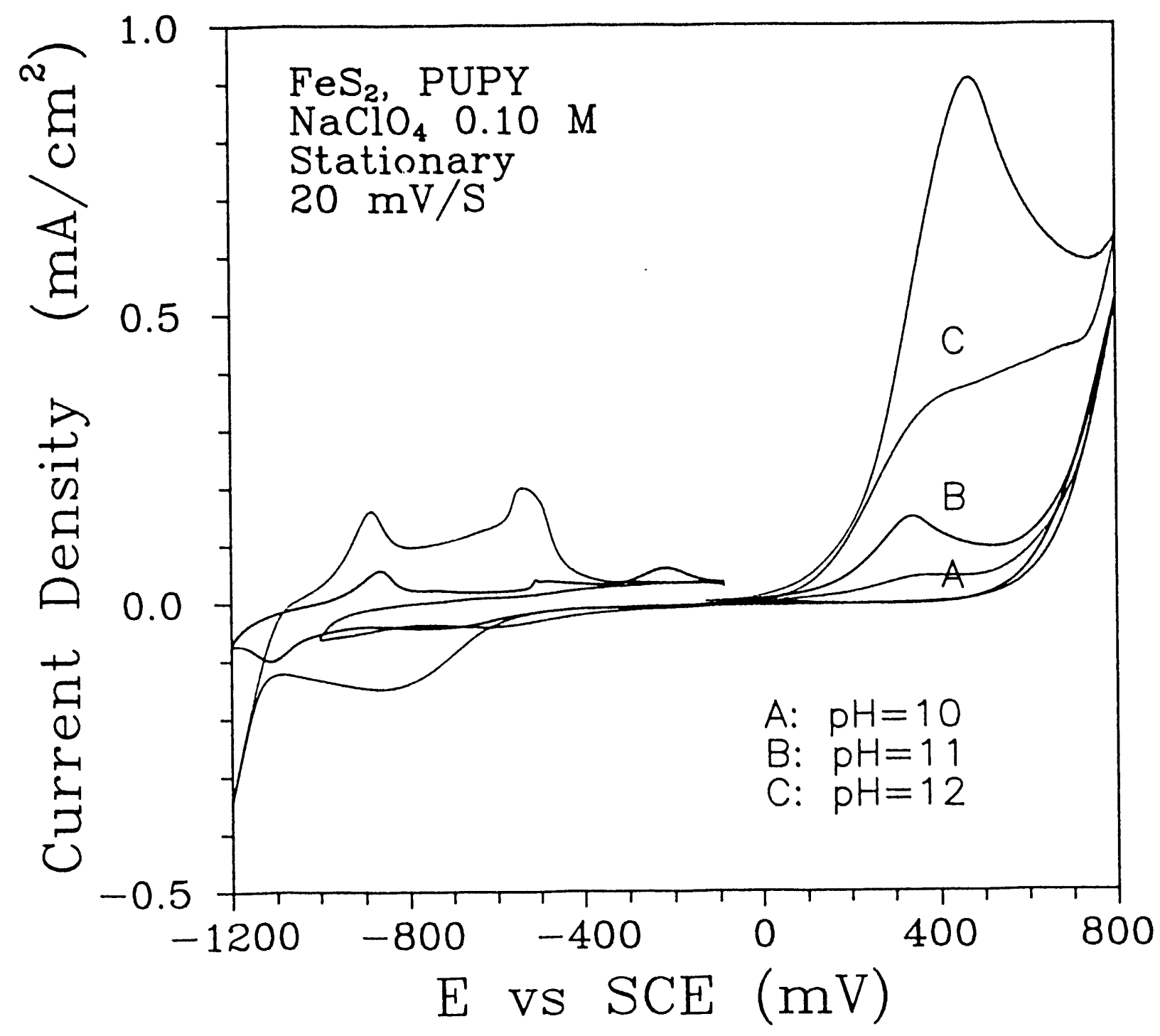

Fig.26 Cyclic voltammograms of the stationary PUPY electrode at different $\mathrm{pH}$ solutions. 


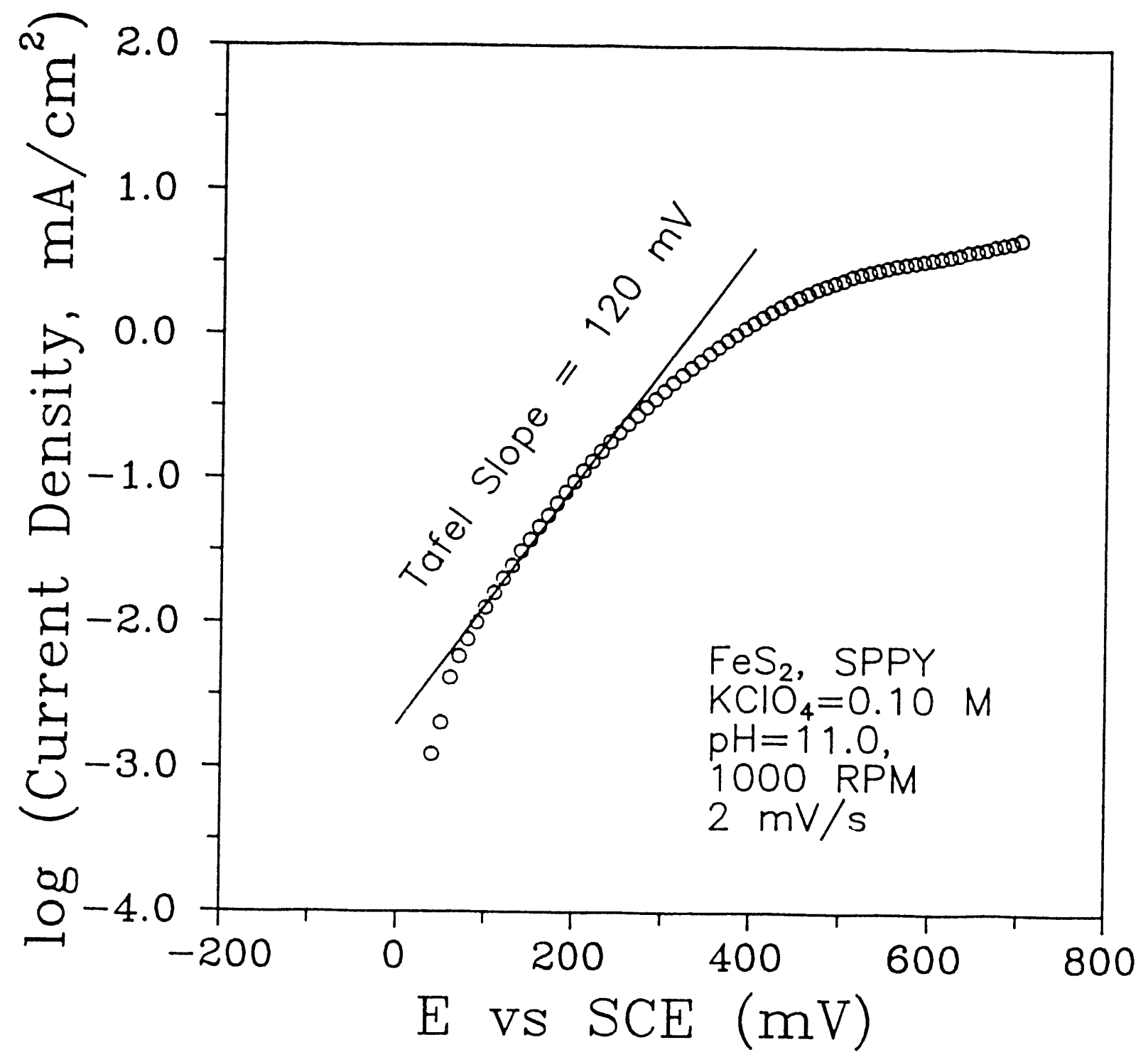

Fig. 27 Tafel slope of the rotating SPPY electrode. 


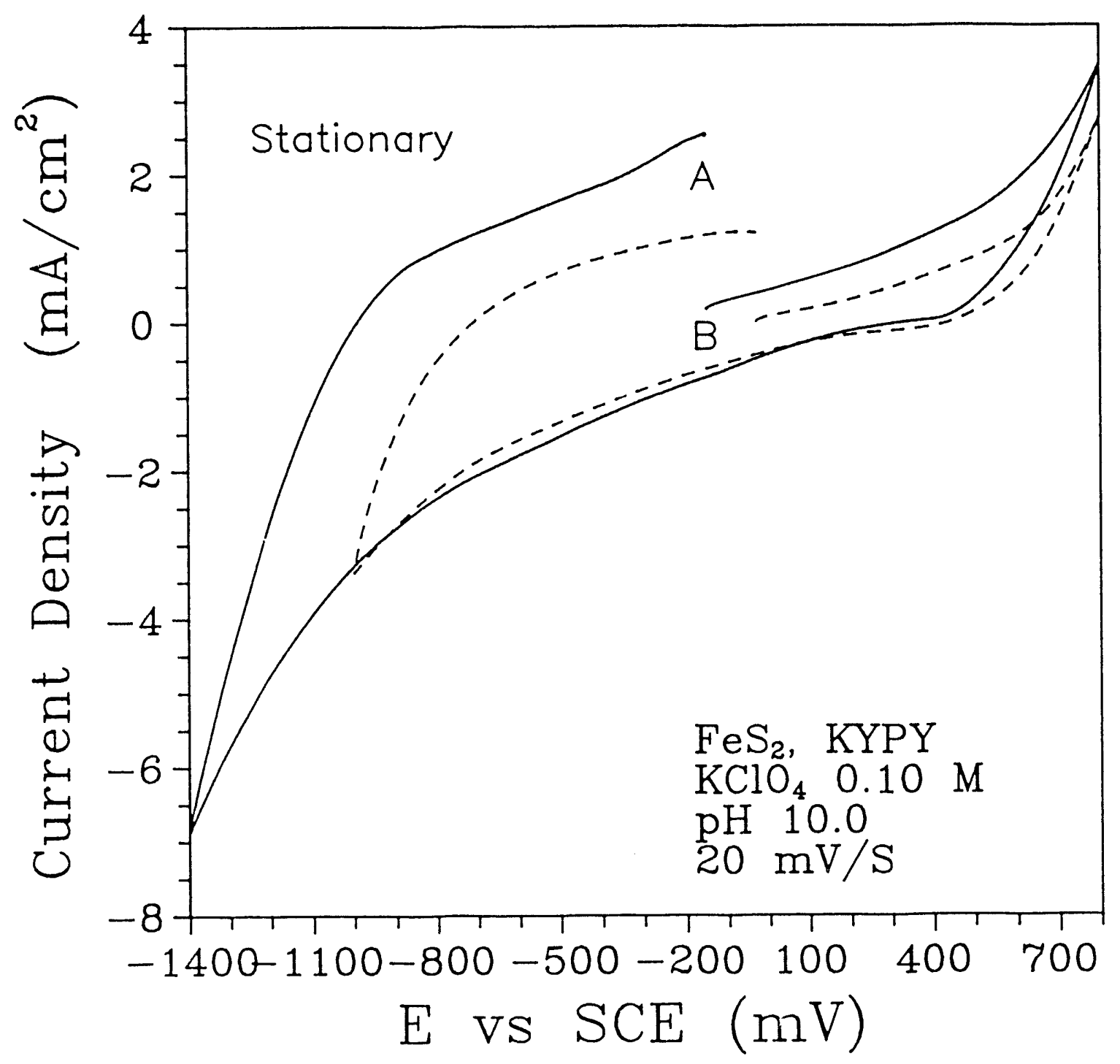

Fig. 28 Typical cyclic voltammograms of the KYPY electrode. The characteristics are nearly independent of the solution $\mathrm{pH}$. 

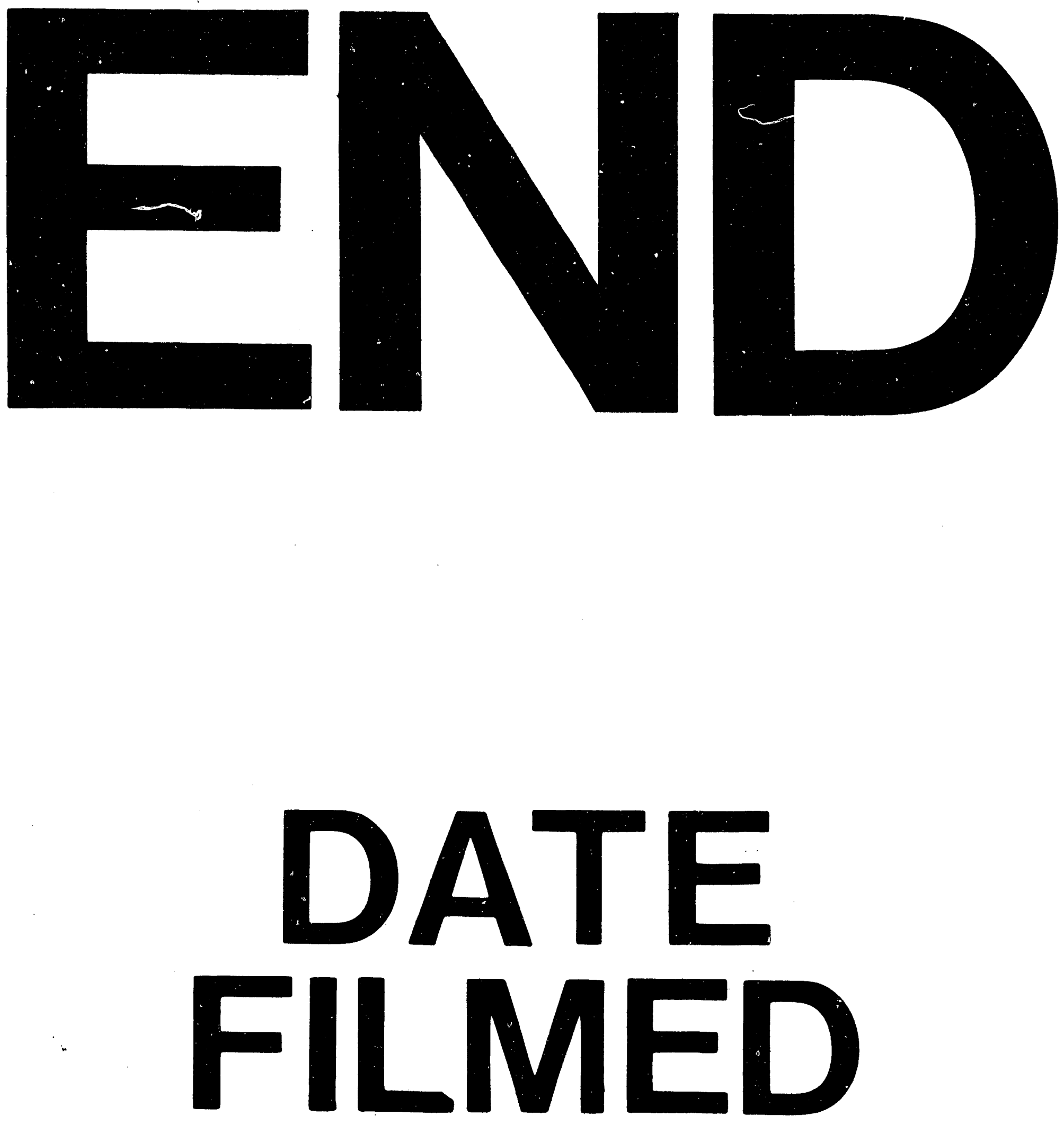

1

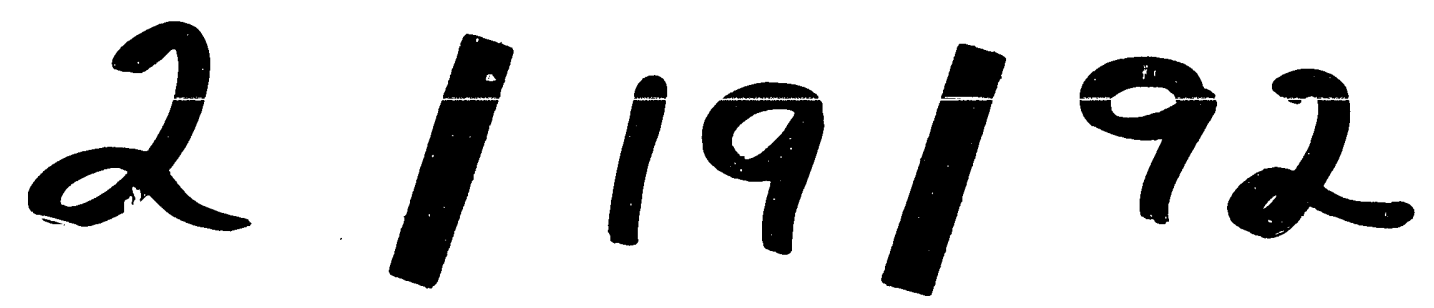




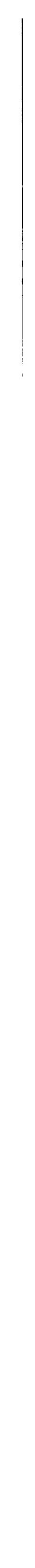

